\title{
TOPONIMIA INDÍGENA DE COSTA RICA
}

\author{
Miguel Ángel Quesada Pacheco
}

\begin{abstract}
RESUMEN
El artículo reúne, analiza y estudia los nombres de lugar (topónimos), de ríos y lagos (hidrónimos) y poblados (ecónimos) que descienden de lenguas indígenas costarricense y que están esparcidos por todo el territorio nacional. El fin es recopilar la mayor cantidad de topónimos posible, empleados hoy en día en el territorio nacional, detectar el origen de cada uno de ellos, y contribuir al estudio de las lenguas indígenas habladas en Costa Rica a través de los topónimos, orónidos, hidrónimos y ecónimos.

Palabras clave: toponimia, lenguas indígenas, historia lingüística, léxico, etnolingüística.
\end{abstract}

\begin{abstract}
This article gathers, analyses and studies place, river, lake and town names which descend from Costa Rican indigenous languages and are to find throughout the country. Its aim is to gather as many toponymics as possible, which are used today in Costa Rica, to find out the language that gave origin to it, and to contribute to the study of indian languages in Costa Rica.

Key words: toponimy, native American languages, Historical linguistics, lexicon, etnolinguistics.
\end{abstract}

\section{Justificación y objetivos}

El presente estudio representa una rama del macroproyecto fundado por la profesora Flor Garita, el cual lleva como título Toponimia de Costa Rica, inscrito en el Instituto de Investigaciones Lingüísticas (INIL) de la Universidad de Costa Rica con las siglas 745-93-203. Este proyecto representa un avance muy significativo en la recopilación, tabulación y análisis de los nombres de lugar, ríos, cerros y pueblos del territorio nacional (cfr. Garita 1995, 1997, 1998a y 1998b, Chang 1999). Como rama del mencionado macroproyecto, el presente estudio (inscrito bajo las siglas 745-95-299 en el INIL) intenta alcanzar las siguientes metas:

Dr. Miguel Ángel Quesada Pacheco. Profesor de la Universidad de Costa Rica y de la Universidad de Berge (Noruega). Correo electrónico: miguel.Quesada@roman.uib.no

Recepción: 31- 7- 2007

Aceptación: 5- 9- 2007 
a) recopilar la mayor cantidad posible de toponímicos indígenas, empleados hoy en día en el territorio nacional;

b) detectar la afiliación lingüística de cada uno de ellos, y

c) contribuir al estudio y conocimiento de las lenguas indígenas habladas en Costa Rica a través de dichos nombres.

Los objetivos específicos son los siguientes:

a) Revisar todos los trabajos sobre toponimia realizados en Costa Rica durante las últimas décadas;

b) De dicha revisión, hacer un inventario de todos los nombres de lugar (topónimos), de ríos, lagos y lagunas (hidrónimos), de pueblos (ecónimos) y de accidentes topográficos (orónimos) presentes en todo el país, que muestren grandes probabilidades de tener origen indígena.

c) Buscar y determinar el origen de dichos nombres;

d) Organizar los toponímicos en orden alfabético, anotando, en la medida de las posibilidades, las coordenadas geográficas localizadoras.

El proyecto surge de la necesidad de montar un marco de referencia, tanto lingüístico, como etnográfico e histórico, para el análisis y estudio de los nombres de lugar (topónimos), de ríos y lagos (hidrónimos) y poblados (ecónimos) que descienden de lenguas indígenas y que están esparcidos por todo el territorio nacional.

\section{Marco teórico}

Tradicionalmente se ha entendido la toponimia como la disciplina científica que estudia los nombres de lugar y sus transformaciones a través del tiempo. Nos da cuenta de migraciones de pueblos, conquistas, colonizaciones, cambios de lenguas, de lenguas muertas, valorización de una tierra y etapas sucesivas de desarrollo cultural. Dentro del concepto de nombres de lugar se circunscriben asimismo los nombres de ríos, lagos o lagunas (hidronimia), los de accidentes topográficos (orónimos), los de poblados (ecónimos) y los nombres de divinidades (hagiónimos).

La toponimia ha ejercido un interés avasallador en el campo de las ciencias sociales, en vista de su función interdisciplinaria: la lingüística, la geografía, la etnografía, la historia y la sociología, para citar algunas ciencias, se favorecen de la toponimia y coadyuvan en su quehacer, cuando se trata de averiguar nombres de lugar, su antigüedad, sus características y sus etimologías. Tal y como expresa Ramón Menéndez Pidal (1968: 5):

\footnotetext{
Los nombres de lugar son viva voz de aquellos pueblos desaparecidos, transmitida de generación en generación, de labio en labio, y que por tradición ininterrumpida llega a nuestros oídos en la pronunciación de los que hoy continúan habitando el mismo lugar, adheridos al mismo terruño de sus remotos antepasados; la necesidad diaria de nombrar este terruño une a través de los milenios la pronunciación de los habitantes de hoy con la pronunciación de los primitivos.
}

El estudio de los nombres de lugar nos puede servir para descubrir vestigios de poblaciones más antiguas (fósiles toponímicos), pues es ante todo a la montaña y a los ríos a que se les da un nombre al inicio, el cual es adaptado por las poblaciones sucesivas. Estos sitios reciben un nombre en tanto la comunidad hablante tenga necesidad de distinguirlos. Si no, se le puede llamar «El Río» o bien «La Colina», etc. A medida que se tiene comunicación con otros pueblos, se hace necesario distinguir el río de un lugar con el río de otro, etc. por medio de calificativos como el color u otra característica: «Los montes azules», «Río Grande», etc. 
Asimismo, con este tipo de estudios se puede determinar, hasta cierto punto, la extensión de una lengua o dialecto, tanto en el pasado como en el presente, y detectar palabras arcaicas u obsolescentes de una lengua.

Fonéticamente, la toponimia es una palabra como cualquier otra, sometida a las leyes de la fonética. Semánticamente, empero, y al contrario de los nombres comunes, los de lugar se fosilizan a un ritmo relativamente rápido, pierden pronto su significación primaria: su vida semántica se para desde su formación. Sin embargo, esto puede llevar a cambios en la actitud de los habitantes, en caso de que el nombre llegue, por distintas circunstancias, a asociarse con palabras no muy aceptadas. Por ejemplo, en Costa Rica los nombres Pacaca, Sietecueros, Zapatón, Zoncuano han llevado a sus habitantes a sustituirlos por otros de más prestigio.

De acuerdo con Artemisa (1991: 22), hay ciertos aspectos que deben tenerse presentes a la hora de delimitar los factores que han influido en el origen de un topónimo:

1. particularidades del terreno;

2. flora y fauna del lugar;

3. presencia de minerales;

4. $\quad$ impresiones que tiene el hombre de un lugar a primera vista;

5. ritos religiosos y costumbres;

6. orientación que da el lugar a sus habitantes;

7. contraposición de homónimos;

8. nombres de voces de lenguas extintas del lugar;

9. fenómenos fonéticos que operan en el topónimo; por ejemplo, en La Hoya, pronunciado [la'hoja], con retención del fonema glotal /h/ medieval;

10. relacionar la toponomástica con otras disciplinas.

Debido a lo anterior, el toponimista debe apoyarse en:

a) la fonética histórica, en particular de la lengua o dialecto a que pertenecen las palabras donde se han desarrollado. Deberá, por ejemplo, manejar conceptos como asimilación, disimilación, aglutinación (de dos palabras), formación regresiva, etimología popular, etc. Ej.: Caesar Augusta > Zaragoza.

En este punto es también importante que el toponimista tenga conocimientos de etimología popular, para desviar falsos orígenes a la palabra en cuestión: en Costa Rica: Turrialba, La Joya, Tarbaca.

b) la arqueología: en este caso, especialmente si el estudioso de la toponimia quiere dedicarse al origen de nombres indígenas, para probar que, efectivamente, el grupo indígena en cuestión allí existió. Por ejemplo, el engaño a que pueden llevar al toponimista los nombres de origen azteca en Costa Rica: Chagüite, Guanacaste, Tempate.

c) la geografía: el toponimista deberá conocer la orografía, la hidrografía, los aspectos del terreno y la geografía humana (establecimientos sedentarios, valorización del suelo, tipos ancianos y modernos de cultura, etc.).

d) la geología: la cual da cuenta de las características del terreno: Tierra Blanca, Peñas Blancas, Malpay.

e) la historia: el primer trabajo del toponimista es estudiar las formas antiguas de la palabra que está estudiando. El toponimista deberá consultar archivos, protocolos, testamentos, etc., para determinar la probable fecha de nacimiento del nombre. En América esta tarea no deberá ser tan ardua respecto de los nombres castellanos debido a la conquista relativamente reciente de los españoles, y por conservarse tanta documentación al respecto. 
f) la tradición oral: especialmente importante en pueblos de reciente fundación, como sucede con las localidades hispanohablantes de América. Se debe hablar con las personas mayores y tratar de encontrar una respuesta única; en caso de haber disparidad entre los informantes, al menos una media que dé para interpretar el origen del nombre. Pero, por otra parte, y dada la escasa conciencia histórica de muchas personas, hay gente que no sabe por qué su pueblo se llama como se llama, a pesar de ser su localidad fundada quizás por sus bisabuelos. Al respecto cabe mencionar al viajero alemán Karl von Seebach, quien, en la década de 1860, visitó la provincia de Guanacaste y manifestó su molestia porque los habitantes de la región, según él, a veces ni siquiera sabían cómo se llamaba el río de donde sacaban el agua potable (Seebach 1865: 242, columna 2. La traducción es mía).

Desde una perspectiva lingüística, los estudios de toponimia pueden enfocarse en los siguientes tipos de análisis:

1. Análisis etimológico: nos lleva al origen de la palabra en cuestión, de modo que se puede determinar si son palabras de origen hispánico, de lenguas indígenas americanas, africanas, de otros orígenes, a la vez que nombres de origen incierto.

2. Análisis estructural: se concentra más bien en la estructura interna de la palabra en cuestión, de donde se pueden entresacar las siguientes:

a) estructuras unimembres (nombres propios, nombres comunes, apellidos, nombres mitológicos, de países, nombres derivados, etc.)

b) estructuras plurimembres:

artículo + sustantivo (El Soslayo, Las Cañas, etc.)

sustantivo + sustantivo (Sarchí Norte, Sarchí Sur)

sustantivo + adjetivo (Quebrada Honda, Paso Ancho, etc.)

sustantivo + numeral (Finca 1, Finca 2, etc.)

sustantivo + preposición + sustantivo (Bajo de Arias, Alto del Aguacate, Monte de la Cruz, etc.)

adjetivo + sustantivo (San Rafael, Buen Pastor, Tres Ríos, etc.)

sustantivo + adverbio (Tortuga Abajo, Tortuga Arriba)

3. Análisis onomasiológico: se concentra en el análisis de lo que significa o da a entender el topónimo (expresión de distancia, de irregularidad topográfica, peligro, belleza, grandeza, pequeñez, etc.). Para esta tarea se parte de los siguientes criterios extralinguiísticos:

a) Criterio topográfico: características topográficas o físicas del territorio que denominan, la fauna y la flora: La Sierra, La Flor, El Tigre, Buenos Aires, Honduras, Puerto Rico, Costa Rica, Río Claro, Río Sucio, etc. Dentro de este criterio se podrían señalar aquellos nombres que dan testimonio de la importancia de las vías de comunicación en la orientación geográfica y descubre viejas vías de comunicación: La Legua, El Cruce, Las Juntas, El Empalme, El Paso, Paso Real, La Trocha, etc. También aquellos que resaltan un rasgo biológico: El Naranjo, Gran Caymán, La Uvita, Punta Mona.

b) Criterio sociocultural: bajo este criterio se estudian nombres que reflejan hechos de la vida social de la comunidad:

1- nombres que recuerdan a sus propietarios o fundadores, o bien algún benefactor

o persona de renombre (América, Colombia, Bolivia, El Bajo de Arias, Ciudad Quesada, Ciudad Colón, Ciudad Neilly, Ciudadela Kennedy)

2- los que hablan de la actividad material del hombre (Bajo Máquinas, El Aserradero, etc.) 
3- nombres que recuerdan a las divinidades (Santiago, Santa María, La Virgen, San Juan)

4- nombres relacionados con deidades mitológicas (Sivorí)

5- nombres relativos a alguna actividad industrial de importancia: El Tejar, etc.

6- nombres que dan testimonio de los sitios de descanso: El Sesteo.

c) Criterio histórico: se trata de identificar nombres que recuerdan algún acontecimiento o efemérides. Por ejemplo, dentro de este criterio se podrían reunir toponímicos que muestran colonizaciones que se superponen unas con otras. Así, en un país latinoamericano los nombres nos dan idea de poblamientos africanos (Palenque en América del Sur), ingleses (Montego Bay, Greytown, Bluefields), holandeses (Willemstad en Curaçao), o de colonización española (Cuenca, Nueva Segovia, Nueva España, Nueva Granada). En España, al lado de los nombres españoles se encuentran nombres árabes (Albarracín, Algeciras, Guadalquivir), nombres romanos (Zaragoza) y nombres prerromanos (Cádiz) o preindoeuropeos (Bilbao). Por otra parte, algunos nombres revelan que el sitio estuvo fortificado: Palenque, Castillo Viejo, El Castillo.

d) Criterio psicológico: nombres que denotan cierta actitud o capricho de los que le dieron el nombre al lugar (El Desengaño, La Calma, Las Delicias, Cabo Gracias a Dios, etc.).

\section{Marco metodológico}

En el caso que nos ocupa, propiamente la toponimia de origen indígena, hay que tomar en cuenta dos aspectos: la extensión geográfica de las lenguas que se han hablado en el territorio nacional, y la delimitación de los nombres susceptibles de ser catalogados como originarios o afines a estas lenguas. Para llevar a cabo esta tarea y recopilar los nombres de lugar, ríos, pueblos y montes que fueran de origen indígena, se revisaron todos los trabajos de toponimia más recientes, particularmente los que tuvieran que ver con el proyecto Toponimia de Costa Rica (Bolaños et al. 1994; Garita 1995, 1997, 1998a, 1998b; Chang 1999, 2003). Una vez revisados, se procedió a la selección de dichos nombres. La tarea se facilitó en gran manera porque los autores consultados ya tenían en sus estudios un apartado sobre el origen de los nombres reunidos por ellos. Pero además se revisaron todos los nombres para asegurarse de que no quedara ninguno extraviado, a la vez que se analizó la lista de nombres de origen incierto, con el fin de detectar algún nombre de origen indígena.

En lo pertinente a la determinación del origen indígena de la palabra en cuestión, se revisaron los diccionarios de lenguas indígenas a mano, además de trabajos especializados sobre la estructura de las lenguas indígenas del país (Margery 1989 y 1996; Quesada Pacheco 1996; Quirós 1986, 2002). Como complemento a estas pesquisas lexicográficas se consultó a personas hablantes o conocedoras de dichas lenguas. En este sentido, ha sido de gran apoyo la colaboración dada por Feliciano Elizondo y Alí García Segura, hablantes de bribri, de doña Paulina Leiva (q.d.D.g.) y de don Nemesio González, hablantes de boruca.

En cuanto a la palabra indígena, se transcribe según las reglas del alfabeto práctico de cada lengua (Margery 1989 y 1996 para el cabécar y el bribri, respectivamente; Constenla y Maroto 1979 para el boruca; Quirós 2002 para el chorotega).

La manera como figuran los nombres en la lista recopilada es:

1. Lema: nombre de lugar, río, lago, laguna, cerro, monte, llano o poblado.

2. De ser posible, nombre del mapa donde figura el lema, junto con las coordenadas geográficas dadas por el Instituto Geográfico Nacional.

3. Nombre de la lengua indígena, o su probable origen indígena. 
4. Constitución léxico-semántica de la palabra indígena y su significado, o probable significado, en lengua española.

5. Únicamente de manera esporádica, pues no forma parte del proyecto de investigación, se cita la primera documentación de los nombres, en caso de tenerse a mano.

Del presente estudio quedan excluidos los toponímicos extintos (por ejemplo Xocci, Acarucá, Zapandí y muchos más). Asimismo, quedan por fuera nombres originarios de lenguas indígenas costarricenses que presentan derivación española (como es el caso de Barucito, Birrisito, Canjelito, Chiquizases, Chirripocito, Dobondecito, Izarquito, Orosilito, Pacuarito, Piuses, Quizarraces, Surazal, Surtubal, Tausito, Tiquiritos, Tirrases, Torrotillo, Turrujal, Yases, Yoses y otras) porque dichas palabras presentan grandes probabilidades de haberse constituido como toponímicos una vez incorporadas al español de Costa Rica.

Es consabido que en Costa Rica hay nombres originarios de lenguas indígenas de otras regiones, que han entrado en el país a través de la lengua española, como sucede con los de origen azteca o náhuatl, los de origen antillano y los de lenguas sudamericanas. Por consiguiente, quedan excluidos del presente estudio.

\section{Limitaciones}

El proyecto, aparte de ser materia de sumo interés, tanto desde la perspectiva lingüística como etnográfica, y social, presenta una serie de tropiezos, los cuales se explican en las siguientes líneas.

a. Toponímicos y lenguas desconocidas

Hay una serie de toponímicos en Costa Rica que claramente no son de origen castellano, de los cuales, además, se tiene constancia de haber existido en el país en tiempos de la Conquista, pero que tampoco pueden afiliarse a una lengua determinada por carecer de información. Cito, a manera de ilustración, los nombres Chomes, Canjel (provincia de Puntarenas), Bagaces (Guanacaste), Siquirres (provincia de Limón). Naturalmente, se han incluido en la lista, pero se han debido calificar como "de origen desconocido".

Por otra parte, hay nombres de origen conocido, pero que, debido a cambios correspondientes a la evolución de un idioma, no se conoce exactamente o del todo su significado o parte de su significado. Lo anterior sucede, por ejemplo, con la palabra Cansot (provincia de Puntarenas), cuyo significado se conoce parcialmente, ya que, si bien se sabe que Can- tiene que ver con el sentido de 'piedra' en boruca, nadie en Boruca es capaz de saber qué quiere decir -sot. En la misma categoría parece estar el ecónimo Tilarán, cuyo segmento ti- muestra relación con la palabra 'agua', presente tanto en huetar como en guatuso (o maleku), como así lo atestigua la fuente colonial que da su significado'; sin embargo, se desconoce el origen de -larán, que no calza con ninguna palabra maleku ni con lo poco que se conoce del huetar ${ }^{2}$.

b. Diversidad de significados en una lengua

No todos los informantes consultados en los trabajos de investigación sobre el origen de una palabra se pusieron de acuerdo en dar un sentido único. En estos casos se apuntan todos los significados aportados. 
c. Confluencia de sentidos en dos lenguas

Una palabra podría venir de dos lenguas distintas. Esto es particularmente notable con los nombres de origen bribri o cabécar, dada la proximidad genética entre estos dos idiomas.

Pero también podría suceder con otras lenguas, como ocurre con el término Burú, (cerros de la provincia de Puntarenas), el cual podría provenir del bribri bulú 'jefe, cacique, rey', como también, a manera de exportación, de la palabra huetar burú. El presente estudio contempla ambas posibilidades de origen y las explica.

\section{d. Disención entre escritura y fonética}

Uno de los obstáculos más grandes con los que se ha topado ha sido la manera como la palabra de origen indígena figura escrita en el alfabeto práctico castellano. Ha habido momentos en que los informantes indígenas no logran columbrar un sentido en su lengua a partir de las grafías como figura la palabra en las listas de toponímicos. Esto, naturalmente, se debe a la adaptación del término a la fonética y al alfabeto práctico del español. Al carecer este idioma romance en su inventario fonológico de fonemas tales como, por ejemplo, los glotales, el palatal fricativo sordo y los tonemas, el hablante hispano se ve en la necesidad de adaptar el término a la fonología y escritura castellanas, por cuya causa muchas veces se hacen irreconocibles los términos ante la vista y el oído de las personas que hablan la lengua que tiene que ver con el término.

Aun así, ha sido posible, en la mayoría de los casos, identificar el nombre en cuestión y dar su etimología. En caso contrario, se ha dado la explicación correspondiente.

\section{Lenguas y grupos indígenas de Costa Rica ayer y hoy}

Costa Rica, con una superficie de $51.000 \mathrm{~km}^{2}$, ha albergado en su territorio a varias etnias indígenas, las cuales, en mayor o menor grado, han contribuido a conformar la toponimia del país ${ }^{3}$. Los grupos etnolingüísticos más importantes y mejor conocidos son, en orden alfabético, los siguientes ${ }^{4}$.

\section{Borucas}

Están situados en las reservas indígenas de Boruca y Curré, al sureste de la provincia de Puntarenas. Su lengua conforma una sola rama de la familia ístmica de la estirpe chibchense.

Los borucas han dejado abundantes huellas de su lengua en la toponimia de la región habitada por ellos. Boruca, Yimba, Gridún y Cansot son algunos ejemplos ilustrativos.

\section{Botos (o votos)}

Estaban situados en las llanuras del norte de Costa Rica, a uno y otro lado del Río San Juan. E. Conzemius (1927: 298) destaca que los indios botos del siglo XVI son los ascendientes de los indios ramas de Nicaragua. En efecto, un dato no visto por Conzemius, que confirma su teoría sobre la localización de los botos a una y otra banda del río San Juan, frontera actual entre Costa Rica y Nicaragua, es una carta de 1591, en la cual se lee: 
No se sabe a ciencia cierta qué toponímicos de la región norte del país puedan ser de origen boto. Quizás el río Sarapiquí -escrito Ciripiquí en los manuscritos coloniales, tal y como se aprecia en la cita anterior- sea un testimonio de este grupo étnico.

\section{Bribris}

Están situados en la vertiente atlántica (provincia de Limón), dentro de las reservas indígenas de Cocles, Talamanca Bribri y, en la vertiente del Pacífico (provincia de Puntarenas), las de Salitre y Cabagra. Junto con el cabécar, forma la subfamilia viceítica de la familia ístmica de la estirpe chibchense.

Toda la región poblada por los bribris mantiene nombres originarios de su lengua.

\section{Buglés o bocotás}

Habitan los mismos territorios que los guaymíes e inmigraron a Costa Rica con estos. Su lengua, junto con el guaymí, conforma la subfamilia guaymíica de la familia ístmica de la estirpe chibchense. Los bocotás siempre han habitado y migrado junto con los guaymíes, razón por la cual se les conoce también como "guaymíes sabaneros" (Abarca 1985: 10). Al igual que los guaymíes, tampoco ha dejado esta lengua huellas en la toponimia costarricense.

\section{Cabécares}

Habitan la Cordillera de Talamanca, dentro de las reservas indígenas de Nairi-Awari, Chirripó, Tayni, Telire, Talamanca Cabécar y, por la vertiente del Pacífico Sur, en Ujarrás. Otros se encuentran diseminados por el cantón de Buenos Aires, provincia de Puntarenas. Su lengua pertenece a la subfamilia viceítica de la familia ístmica de la estirpe chibchense.

La vertiente atlántica y la pacífica sur contienen abundantes nombres de origen cabécar.

\section{Catapas y tices}

Situados cerca de la actual ciudad de Barva, en la parte norte del Valle Central, de cuyas afinidades lingüísticas y rasgos culturales nada se ha conservado. Constenla (íbidem) hace notar que estos dos pueblos fueron repartidos por Perafán de Ribera junto con los botos y los corobicíes, de modo que se podría pensar que eran afines a los botos. Si de estos dos grupos no se sabe casi nada, menos sabremos de toponímicos originarios de ellos.

\section{Chorotegas}

A la llegada de los españoles, los chorotegas ocupaban la actual provincia de Guanacaste, más una sección de la banda oriental del Golfo de Nicoya, región llamada Choluteca la Vieja, y donde estaban los poblados de Gurutiña u Orotiña, y Chomes (Tous 2002: 149-150). Además, se extendían por Nicaragua y Honduras (Lehmann 1920: 822). Fueron los primeros del actual territorio costarricense en ser sojuzgados.

La única lengua documentada hasta la fecha es el chorotega, hoy extinta, y cuyos descendientes habitan hoy la reserva indígena de Matambú, en la Península de Nicoya, provincia de Guanacaste. 
La lengua chorotega, al igual que el chiapaneco, perteneció a la familia otomangue. Del chorotega se conservan unas 300 palabras más algunas frases (cfr. Quirós 1984, 2002). De esta lengua se conservan bastantes nombres en la provincia de Guanacaste, en Nicaragua y en Honduras. En Guanacaste se pueden citar: Nicoya, Nandayure, Nambí, Nosara y Curime.

\section{Coctus y durucacas o turucacas}

Estaban situados en las márgenes del Río Grande de Térraba, en la Zona Sur. Respecto de estos dos grupos, también soy de la opinión de que pudieron estar muy cerca de los borucas, no tanto por su cercanía geográfica, sino porque, al igual que los quepos, fueron reducidos junto con los borucas en el siglo XVII (L. Fernández 1889: 171). Además, parece que en el siglo XVI estaban todos los tres grupos bajo el mando de un solo cacique, Giriara, que gobernaba Borucaca -hoy Boruca- y Turucaca (Quesada Pacheco 1994: 16). Por último, la terminación - caca de la palabra Turucaca parece tener relación con la misma de Burucaca (en lengua boruca bruncajc 'boruca' y cajc 'oquedad').

Quizás el nombre Coto Brus sea de origen coctu. De ahí en adelante, nada se sabe de nombres originarios de esta etnia.

\section{Corobicíes}

Habitaron la banda oriental del Golfo de Nicoya (Tous 2002: 205). Según Fernández de Oviedo, eran de otra lengua apartada de todas las que se han dicho en esta historia (cit. por C. Meléndez 1978: 35) es decir, de los chorotegas y de los nicaraos. W. Lehmann (1920: 375- 379) considera que son los antecesores de los guatusos actuales, pero E. Conzemius (1927) los agrupa entre los indios ramas. Al respecto afirma A. Constenla:

Si los corobicíes eran ramas, representaban, entonces una de las divisiones de la estirpe chibchense: la familia vótica, a la que pertenece también el guatuso y, probablemente, perteneció el huetar. (Constenla 1995: 15).

Tous (2005: 146, 150 y 205) afirma que los corobicíes eran de origen sureño y estaban en una zona fronteriza con los chorotegas, razón por la cual no los incluye dentro de los grupos indígenas de la Gran Nicoya.

\section{Guatusos}

Habitan la reserva indígena de Guatuso, en la sección noroeste de la provincia de Alajuela, cerca de la frontera con Nicaragua. La primera mención que se hace de ellos data de 1756. Su lengua, conocida con el nombre de guatuso o maleku, junto con el rama (Nicaragua) pertenece a la familia vótica de la estirpe chibchense.

Los guatusos han dejado algunas huellas de su idioma en la toponimia de la Zona Norte, tales como Cóter, Upala y Tonjibe.

\section{Guaymíes}

Habitan las reservas indígenas de Coto Brus, Abrojo Montezuma, Osa y Conte Burica, al sureste de la provincia de Puntarenas, colindando con Panamá. Su presencia en Costa Rica data de algunas décadas, pero durante la Colonia habitaban la región de Bocas del Toro, en la vertiente atlántica, hoy jurisdicción panameña pero perteneciente a Costa Rica hasta 1944. En virtud de 
esta situación, y después de varios debates y revueltas, los guaymíes, que durante las últimas cuatro décadas se han asentado dentro de las actuales fronteras costarricenses, fueron declarados, según la ley \#7225 del 19 de abril de 1991 de la Asamblea Legislativa de Costa Rica, "costarricenses por nacimiento". Su lengua es parte de la subfamilia guaymíica de la familia ístmica de la estirpe chibchense, pero no ha dejado huellas en la toponimia de Costa Rica.

\section{Huetares}

Pueblan hoy en día la región sur de la provincia de San José, en el Valle Central. Habitan en dos reservas indígenas, la de Quitirrisí (cantón de Mora) y la de Zapatón (cantón de Puriscal), pero he detectado pobladores de origen huetar en otras zonas de los cantones de Puriscal y Acosta, especialmente en las márgenes del Río Grande o de Candelaria, además de los poblados de Cerritos y El Nene, en el cantón de Aguirre, provincia de Puntarenas. La presencia de estos grupos en la provincia de Puntarenas se debe a migraciones que ocurrieron durante la primera mitad del siglo XX.

Los huetares fueron el grupo más importante y poderoso del país durante el siglo XVI; poblaban todo el Valle Central hasta la costa del Pacífico y, por el oeste, la Cordillera de Guanacaste, razón por la cual los españoles los llamaron en un principio "indios de la sierra" (cfr. M. Peralta 1883: 54). Su idioma fue considerado lengua general de la Provincia de Costa Rica a principios de la Colonia (Quesada Pacheco 1990: 13).

El huetar debió extinguirse a principios del siglo XVIII. De esta lengua, pese a su importancia durante el siglo XVI, no han quedado textos. Por testimonios se sabe que existió un catecismo en lengua huetar (Quesada Pacheco 1990: 12- 13), pero hasta la fecha no se ha dado con su paradero 5 . En un esfuerzo por rescatar lo poco que queda de esta lengua, he podido recopilar unos 650 lexemas, de los cuales 200 son palabras comunes y 450 nombres propios $^{6}$. A pesar de lo escasamente documentada, Constenla (1984) ha probado su afinidad chibcha, mediante ocho étimos que ha comparado con las lenguas del área. Utilizando un número mayor de cognados, he propuesto una subclasificación del huetar como cercano al guatuso (Quesada Pacheco 1992: 86). El guatuso y el rama son miembros de la familia vótica, dentro de la estirpe chibchense.

El huetar ha dejado abundantes huellas en la toponimia del Valle Central de Costa Rica y en zonas periféricas donde estuvieron presentes. Curridabat (antiguo Currirava, también conocido como Parrosquirrís), Tacacorí, Pocares, Aserrí, Tibás, Tayutic, Tiribí, Tucufres y Chicuá son algunos de ellos.

\section{Mexicanos o náhuatl}

Estaban en la actual zona fronteriza con Panamá, por la vertiente atlántica. En cuanto a la veracidad de su presencia en la región, el cronista Juan de Torquemada, en 1615, afirma, refiriéndose a grupos de procedencia mesoamericana:

También se dice que de esta generación de indios fueron algunos de ellos atravesando y aportaron a la Mar del Norte, y cerca del desaguadero está un pueblo de ellos y hablan en lengua mexicana no tan corrupta como estotra de los pipiles (Torquemada, cit. por M. Tous Mata 2002: 144).

A este grupo étnico se le conoció como "mexicanos" o "chichimecas", y se señala a Yzolin como su cacique en 1562 (Archivo General de Indias: Patronato 27, ramo 23, 2). Su lengua, que, al decir Torquemada, era "no tan corrupta", o sea, que estaba más cercana 
al náhuatl clásico, se conservaba durante el siglo XVI, y debió ser bastante afín al azteca, puesto que, según la crónica de Pedro Gallegos, de 1570, algunos conquistadores, que habían aprendido náhuatl en México, pudieron hablar con estos individuos:

hallamos unos indios de nación mexicanos, los cuales se holgaron mucho con nosotros, porque les hablá-

bamos su lengua (Gallegos 1990: 16).

Sin embargo, de acuerdo con M. Tous (2002: 145), la presencia de estos grupos aztecas fue más bien de reconocimiento del territorio, y no de conquista y poblamiento:

las excavaciones arqueológicas realizadas a partir de la década de 1980 muestran que estas migraciones no fueron del tipo colonia-frontera, sino que se realizaron de una forma paulatina y, aparentemente, involucraron a pocos individuos al contrario de lo que afirman las crónicas.

Todavía a principios del siglo XVII, en 1606, hubo intentos de conquistar a los aztecas de la vertiente atlántica y reducirlos al dominio español ${ }^{7}$.

Por el lado del Pacífico, Tous (2002: 146) indica la presencia de nicaraos, de lengua náhuatl, en la zona fronteriza entre Rivas y Guanacaste; además, se afirma que hubo un enclave náhuatl en Bagaces, provincia de Guanacaste, pero de cuyo grupo se tiene muy poca información (Arroyo 1971: 171; Healy 1974: 32).

Quizás con excepción de la palabra Tempisque, cuya presencia en la provincia de Guanacaste está documentada desde inicios de la Colonia, el náhuatl en Costa Rica no ha dejado huellas en la toponimia costarricense. Ahora bien, existe una mal fundada idea de que nombres de origen náhuatl como Guanacaste, Jicaral, Zapote, Los Chiles, Guápiles, Montezuma, Chagüite y tantos otros que abundan en calidad de toponímicos en Costa Rica, son testimonio de la presencia de los aztecas de época antigua (cfr. Ferrero 1986: 100- 101). Lo cierto es que estas palabras dieron nombres a muchos lugares del país a través de la lengua española; es decir, comenzaron a actuar como topónimos una vez incluidos en el vocabulario patrimonial castellano. Al respecto afirma V. Arroyo (1971: 171):

No hay influencia del náhuatl en las lenguas indígenas costarricenses. Los nahuatlismos del habla popular, pues, tienen que haber llegado durante la colonia, especialmente, traídos por funcionarios de la colonia y otros inmigrantes que habían vivido en regiones americanas como Méjico, Guatemala, El Salvador, etc., donde tales voces estaban vigentes.

Lo anterior explica que, por ejemplo, en el Valle Central, donde no se tiene noticia documental de la presencia náhuatl, haya muchos lugares con nombres de este origen.

Un fenómeno muy similar sucedió con voces de origen antillano y dieron nombres a lugares del país (Bejucal, Barbacoas, Bijagual y Guayabo, por ejemplo). Sin embargo, no se tiene noticia de que los grupos étnicos antillanos estuvieran presentes en Costa Rica en algún momento de la historia precolombina.

\section{Miskitos}

No son ni han sido un grupo que ha habitado territorio costarricense de manera permanente. La presencia de nombres miskitos en la costa atlántica de Costa Rica responde más bien a contactos comerciales y militares, que de asentamientos duraderos. Los miskitos, llamados durante la Colonia zambos-mosquitos, habitan hoy en día la costa atlántica de Honduras (Departamento de Gracias a Dios) y la de Nicaragua (Departamento de Zelaya, Región Autónoma Atlántico Norte y Región Autónoma Atlántico Sur, entre otras). Durante la época colonial representaron una amenaza para las autoridades de la en ese entonces provincia 
de Costa Rica, ya que con sus frecuentes incursiones a la costa atlántica lograban, sin control de las autoridades, saquear y robar. Por otra parte, mediante este contacto se establecieron lazos comerciales, de cuya presencia se originaron algunos nombres como Cahuita y Sixaola, en la provincia de Limón (cfr. Potthast 1998).

Con las recientes olas inmigratorias de nicaragüenses en Costa Rica se cuentan hablantes de miskito en este país (cfr. http://www.fidh.org/IMG/pdf/costarica2002cerd.pdf), de cuyas cifras no se tiene certera noticia.

\section{Quepos}

Vivían cerca de la ciudad de Parrita, provincia de Puntarenas. Según un manuscrito de 1595 (Gagini 1923: 79) ${ }^{8}$, vivían junto a un río navegable, el cual debe de ser el Río Pirrís o Parrita, y por consiguiente distaban unos $25 \mathrm{~km}$ al oeste de la actual ciudad de Quepos. De la lengua de los quepos no queda más que una palabra, chiro o chirob 'cierta especia' (Vázquez de Coronado 1964: 32 y 46), además de una lista de 93 antropónimos que data de 1616 , y por lo tanto no es posible afirmar nada acerca de sus afinidades lingüísticas. Por el momento, lo único que se puede afirmar, siguiendo a grandes rasgos la configuración gráfica de dichos antropónimos, es que el idioma de los quepos parece haber sido diferente respecto del de sus vecinos, los huetares al norte y los borucas al este, y por lo tanto representaría un conjunto fónico autónomo ${ }^{10}$. Por otra parte, el hecho de que los quepos fueran reducidos junto con los borucas en 1749 (Guevara y Chacón 1992: 119) bien podría servir de argumento para pensar que eran afines a estos.

De origen quepo podrían ser Quepos y Barú.

\section{Quequexques}

Vivían en la zona fronteriza actual de Costa Rica con Panamá, por la costa atlántica. Eran vecinos de los teribes, y en vista de que figuran casi siempre mencionados junto a estos, M. Portilla (1986: 103 y 239, nota 10) considera que pudieron ser una rama teribe.

No se tienen testimonios de toponímicos originarios de esta etnia.

\section{Suerres}

Ocupaban la sección norte de la provincia de Heredia, confinando con el Río San Juan. Su nombre pervive en un hidrónimo, el Río Suerre, en la costa atlántica, y de su lengua se han conservado cinco lexemas, gracias al relato de Girolamo Benzoni (1572/1962) sobre las vicisitudes que pasaron el gobernador Diego Gutiérrez y sus soldados cuando intentaron entrar al Valle Central pasando por el territorio de estos indígenas. El parecido que guardan las cinco palabras con el cabécar llevó a W. Lehmann (1920: 200) a proponer esta lengua como afín a las lenguas de Talamanca. De ser así, pienso que esta lengua pudo haber sido un integrante más de la familia viceítica, formada por el cabécar y el bribri.

\section{Térrabas}

Habitan la reserva indígena de Térraba, al sureste de la provincia de Puntarenas. Son descendientes de los teribes, en la costa atlántica de Panamá, entre Changuinola y Bocas del Toro. Su presencia en Costa Rica responde a una inmigración forzada por parte de los misioneros a finales del siglo XVII. El térraba y el teribe forman la subfamilia tiribí de la familia ístmica de la estirpe chibchense. 
Los térrabas casi no han dejado huellas de su lengua en la toponimia de la zona donde han habitado. Carse, Dobongragua y Dobonde son algunos términos procedentes de esta lengua.

\section{Para concluir}

Un estudio como el presente requiere de mucho esfuerzo investigativo, ya que la determinación del significado de una palabra en calidad de topónimo muchas veces no es tan transparente como uno pensaría. Si la lengua española presenta problemas no resueltos aún en este campo ${ }^{11}$, tanto más se podrá esperar de la toponimia de origen indígena. Véase, por ejemplo, la cantidad de nombres cuyo significado no queda determinado aún. Por otra parte, muchos topónimos ya son de hecho topónimos y nada más que eso; es decir, que no guardan significados primarios ni transparentes, ni siquiera para el grupo étnico que bautizó a sus pueblos, ríos y cerros con dichos nombres. Por ejemplo, las palabras cabecares Juruy, Urán, y las borucas Chamba (o Shamba), Cansot, etc.

Un topónimo sigue el paso del tiempo y su paso no queda desapercibido. A veces guarda en su composición fónica el significado original, otras veces no, lo cual se convierte en un reto para el investigador.

\section{Topónimos}

Agrá: río de Barva, provincia de Heredia (Barva 536 222). Voz de probable origen huetar que designa una planta silvestre de cuyo tronco sale agua potable. Gagini (Diccionario de costarriqueñismos) relaciona la palabra con la española agraz 'uva sin madurar', lo cual considero poco probable, ya que no hay ninguna relación semántica con la planta costarricense ni tampoco se explica la desaparición del sonido final [-s] en el Valle Central, donde este sonido no se aspira ni se pierde.

Agres: río de la provincia de San José (Abra 521 214). Voz de probable origen huetar, de significado desconocido. Parece estar compuesta de dos palabras: *a de origen desconocido, y del sufijo abundancial -cris, que evolucionó en -gres.

Ajcoquichádik: quebrada de la provincia de Puntarenas (Buenos Aires 544 350). Voz de origen bribri que significa quebrada del 'bejuco de canasta'; de ajkö 'canasta', kichà 'bejuco' y di' 'río'. El sonido /k/ de final de palabra debe de ser una adaptación fonética castellana a raíz del sonido glotal bribri.

Aká: cerro de la provincia de Limón (Pittier 574 344, Durika 539 370). Del bribri aká 'pico de ave'.

Akó: cerro de la provincia de Limón (Durika 541 268). Del bribri akó 'tapezco'.

Aktú: río de la provincia de Limón (Kamuk 562 362). Del bribri ak 'roca, peñasco’ y tö 'dentro' ('dentro de la roca').

Akukia: río de la provincia de Limón (Siola 568 373). Según Chang (1999: 107), proviene del bribri akkuëa 'gavilán'. 
Akum: río de la provincia de Puntarenas (Kamuk 547 352). Voz de origen bribri que designa dicho río (àköm).

Ambri: quebrada de la provincia de Limón (Sukut 579 369). Del bribri ak 'piedra' y bli 'cauce, terreno profundo y ondulado' ('cauce empedrado').

Ámbri: río de la provincia de Puntarenas (Cabagra 553 345). Voz de origen bribri que significa 'cauce de piedras'; de ák 'piedra' y bli 'cauce'. El bribri posee una regla fonética según la cual, ante /b/, el sonido /k/ se vuelve $/ \mathrm{m} /$.

Ambriri: quebrada de la provincia de Limón (Sukut 579 369). Del bribri ak 'piedra', bli 'cauce' y ri 'agua, río' ('río del cauce empedrado').

Ambruí: cerro de la provincia de Puntarenas (Kamuk 553 348). De la misma raíz que Ámbri (ver).

Amburi: quebrada de la provincia de Limón (Sukut 580 367). Del bribri amu 'pita' y ri 'agua'('río de la pita').

Amí: cerro de la provincia de Limón (Durika 522 373). Del bribri ami 'mamá'.

Amó: cerro de la provincia de Limón (Durika 520 376). Del cabécar amó ‘aguacate'.

Amú: cerro de la provincia de Puntarenas (Durica 542 366). Del bribri amù 'pita'.

Amubri: quebrada y poblado de la provincia de Limón (Sukut 580 367). Del bribri amú 'pita' y bli 'cauce' ('cauce de la pita').

Amúo: cerro de la provincia de Puntarenas (Cabagra 562 341). De la misma raíz que Amú (ver).

Amurical: quebrada de la provincia de Puntarenas (General 542 345). Voz de origen bribri que significa 'árbol de la quebrada de la pita'; compuesta de amù 'pita', di' 'río' y kal 'árbol'.

Apó: cerro de la provincia de Puntarenas (Cabagra 571 340). Del bribri apö 'panteón, cementerio'.

Aquiares: río y poblado de Tucurrique, provincia de Cartago (Tucurrique 567 215, 568 214). Voz de probable origen huetar, de significado desconocido.

Araki: cerro de la provincia de Puntarenas (Cabagra 563 345). Del bribri aláki 'hembra'.

Arara: cerro de la provincia de Puntarenas (Kamuk 555 350). Del bribri aláal 'recién nacido'.

Arjbeta: loma de la provincia de Limón (Amubri 580 390). Según Chang (1999: 107), es voz proveniente del bribri que significa 'punta rocosa' (ak 'piedra' y bata 'punta'). 
Arrabará: poblado en Cartago (Istarú 556 207). Voz de probable origen huetar, de significado desconocido.

Arriaz: río de la provincia de Cartago (Istarú 562 219). Voz de probable origen huetar, de significado desconocido.

Aserrí: ciudad de la provincia de San José (Abra 527 205). Voz de origen huetar, de significado desconocido. Su primera documentación en 1562 se refiere al nombre de un cacique indígena y al poblado donde vivía.

Asidbeta: cerro de la provincia de Limón (Pittier 579 341). Según Chang (1999: 107) es voz bribri que significa 'cerro del terraplén o del deslizamiento'.

Atirro: río, fila, cerro y poblado de la provincia de Cartago (Chirripó 593 193, Tucurrique 573 203, Pejibaye 579 196). Voz de origen huetar que designa una planta de fruto comestible.

Bagaces: río y poblado de la provincia de Guanacaste (Monteverde). Voz de procedencia indígena, cuya primera documentación data de 1563 bajo la forma Bagaçi (Vázquez de Coronado 1964). A juzgar por su primera documentación, dicha palabra parece ser de procedencia corobicí, una lengua muy probablemente emparentada con el rama (Nicaragua), de afiliación chibcha, en donde la terminación - ci significa 'agua' (cfr. Constenla 1994).

Bakábeta: cerro de la provincia de Limón (Matama 526 399). Voz de origen cabécar que parece tener relación con la palabra baká 'canastilla en la que el chamán guarda las piedras ceremoniales', en cuyo caso significaría 'cerro de la canastilla de las piedras ceremoniales' (bata 'cerro, punta'). También podría tener relación con baká 'gamalote' (Paspalum fasciculatum).

Bakeí, Bajkei: quebrada de la provincia de Cartago. Voz de origen cabécar que significa ‘dueño’ (wákéi).

Bari: quebrada de la provincia de Limón (Telire 560 364). Del cabécar bali 'vertiente, manantial'.

Barú: río y poblado de la provincia de San José (Dominical 481359 y 482 358). Voz de probable origen indígena pero de afiliación desconocida. Podría tener relación con la antigua lengua de los quepos por dos razones; en primer lugar, su estructura fonética calza con el sistema de sonidos que posiblemente tuvo dicha lengua. En segundo lugar, su ubicación está dentro del radio de acción de los antiguos quepos (Quesada Pacheco 1996c).

Barva: poblado de la provincia de Heredia (Barva 523 223). Voz de muy probable origen huetar, de significado desconocido. Figura mencionado en los manuscritos de la Colonia desde 1590 (Archivo General de Indias, Escribanía 371-B). 
Bechuri: quebrada de la provincia de Limón (Telire 564 384). Según Chang (1999: 107). Del bribri chöli 'vómito'.

Bekis: sabana de la provincia de Puntarenas (Buenos Aires 540 356). Podría provenir del cabécar bëkí 'cierto árbol cuya madera se emplea en la construcción de hachas'.

Bekri: cerro de la provincia de Puntarenas (Kamuk 555 350). De origen no determinado.

Beri: cerro de la provincia de Puntarenas (Cabagra 564 346). De origen no determinado.

Betsik: cerro de la provincia de Limón (Kamuk 569 352). Del cabécar batsik 'cusinga, tucancillo'.

Betsú: cerro de la provincia de Limón (Durika 543 367). Del cabécar batsu 'colibrí'.

Betú: cerro de la provincia de Limón (Durika 544 367). Del bribri batú 'oscuro, negruzco'.

Birrí: quebrada y poblado de la provincia de Heredia (Barva 521 227, 522 227). Voz de muy probable origen huetar, de significado desconocido.

Birrís: río y poblado de la provincia de Cartago (Istarú 559 210). Voz de probable origen huetar, de significado desconocido.

Bita: cerro de la provincia de Puntarenas (Kamuk 553 355). Del bribri bita 'ardilla'.

Bitárkara: cerro de la provincia de Limón (Telire 568 399). Del cabécar biták 'raspaguacal' (Curatella americana) y kal 'árbol' ('árbol de raspaguacal').

Bitey: río de la provincia de Limón (Cahuita 653 185). Del cabécar bitéi 'nombre de un palenque situado en la margen derecha del río de La Estrella'.

Bitsi: cerro de la provincia de Limón (Durika 536 372). Del bribri bitsi 'largo’.

Blei: río y quebrada de la provincia de Limón (Telire 546 395, 546 397). Del bribri bli 'cauce, terreno profundo y ondulado, depresión'.

Blorikal: río de la provincia de Puntarenas (General 540 347). Del bribri blò 'árbol de poró' (Erythrinia costaricensis), di' 'agua', más kal de significado incierto.

Bloye: quebrada de la provincia de Limón (Telire 570 395). Del cabécar boló ‘dulce’ y -yena 'un poco, algo' ('quebrada algo dulce').

Bolorí: río de la provincia de Cartago, tributario de la ribera norte del Chirripó (Chirripó). Voz de origen cabécar que significa 'río del rey', compuesta de bulú 'rey' y rí 'río'. 
Boró: cerro de la provincia de Limón (Durika 523 381). Del bribri boló 'poró' (Erithryna costaricensis).

Boroi: río de la provincia de Cartago (Cuericí 510 401). Del cabécar bolói ‘esponjoso’.

Boruca: quebrada y poblado de la provincia de Puntarenas (General 540 344). Voz de origen boruca que significa 'oquedad de la ceniza', compuesta de brún 'ceniza' y cajc 'oquedad, parte interior'. Esta palabra -en su forma Burucaca- figura documentada por primera vez en las cartas de Juan Vázquez de Coronado (1563) y en boca de huetares.

Bratsi: quebrada de la provincia de Limón (Amubri 584 391). Voz de origen bribri, de significado no determinado.

Broi: río de la provincia de Limón (Matama 527 389). Del cabécar bolói ‘esponjoso’.

Bruncri, Bruncrin: quebrada de la provincia de Puntarenas (General 537 329). Voz de origen boruca que significa 'cruce de ceniza'; compuesta de brún? 'ceniza' y crin? 'cruce, intersección'.

Brurán: sabana de la provincia de Puntarenas (General 540 333). Del boruca brujrán 'leña de río’.

Buclari: quebrada de la provincia de Limón (Matama 529 398). Del cabécar bukulá 'avispa' y ri 'río' ('río de la avispa').

Bugu: fila de la provincia de Limón (Siola 552 375). Voz de probable origen bribri, de significado no determinado.

Bukí: quebrada de la provincia de Puntarenas (Pittier 584 332). Del bribri bukë' 'sapo'.

Bunú: quebrada de la provincia de Puntarenas (Pittier 581 332). Del bribri bùnun 'rana'.

Burí: quebrada de la provincia de Puntarenas (Unión 591 327). Probablemente del bribri bulër 'olomina'.

Buridikur: quebrada de la provincia de Limón (Estrella 643 198). Según Chang (1999: 108), proviene del bribri buri 'grueso' y dukur 'murciélago'.

Burrogres: quebrada de la provincia de Alajuela (Naranjo 222 489). Voz de probable origen huetar, de significado desconocido. El elemento -gres es un abundancial.

Burú: cerros de la provincia de Puntarenas (Pittier 592 330). Voz de origen incierto. Podría provenir del bribri bulú 'jefe, cacique, rey', como también, a manera de exportación, llevada por los que exploraron esos cerros, de la palabra burú que designa un tipo de avispa, en cuyo caso sería de origen huetar. 
Bururak: cerro de la provincia de Cartago. Voz de origen cabécar que significa 'piedra del armadillo zopilote' (bulúr 'armadillo zopilote' (Cabassous centralis), ak 'piedra'.

Buruveri: quebrada de la provincia de Limón (Telire 557 391). De origen no determinado.

Buruy: cerro de la provincia de Cartago. Voz de origen cabécar (ver Boroi).

Cabagra: fila, poblado y río de la provincia de Puntarenas (Pittier 549 342, Cabagra 550334 , 549 343). Del bribri kabákör 'cañablanca'.

Cachabri: quebrada de la provincia de Limón (Amubri 574 384). Del bribri kacha 'achiote' (Bija orellana) y bli 'cauce' ('río del achiote').

Cachí: poblado de la provincia de Cartago. Voz de probable origen huetar que designa una especie de tucán.

Cahuita: poblado de la provincia de Limón (Cahuita 664 192). Del miskito cawi ‘sangrillo’ y ta 'punta' ('punta de los sangrillos') (Chang 1999: 108).

Calveri: río de la provincia de Limón (Estrella 637 191). Del cabécar kal 'árbol' y bli 'cauce' ('río del árbol').

Canchén: quebrada y cerro de la provincia de Puntarenas (Chánguena 535 321, 536 320). Voz de origen boruca que significa 'parte trasera de piedras'; compuesta de cán 'piedra' y chén? 'parte trasera'.

Canforro: fila de la provincia de San José (San Isidro 510 369). Voz de probable origen huetar que designa las cavidades que se forman en los caminos rurales, o bien un camino profundo a causa de las lluvias y del continuo tránsito de personas y animales. Pareciera estar compuesto de dos palabras: can 'tierra' y jorro ‘hueco'. Para dar tales significados me baso en el parecido de dichas voces con las palabras cabécares del mismo contenido, ya que no están documentadas las palabras huetares para 'tierra' y 'hueco'.

Canjel: quebrada y poblado de la provincia de Guanacaste (Venado). Voz de origen indígena, pero de afiliación y significado desconocidos. Su primera documentación data de 1522 y designaba el nombre de un cacique y su poblado, situado en el litoral del Golfo de Nicoya. La presencia de este nombre en el Valle Central (Abra 512 213) se explica por importación.

Cansot: quebrada y poblado de la provincia de Puntarenas (Chánguena 525 324, 526 323). Del boruca cán 'piedra' y sót, de significado desconocido.

Cantú: poblado de la provincia de Puntarenas (Coto Brus 547 320). Voz de origen boruca que significa ‘túnel, hueco' (de can? 'piedra' y túj ‘pedazo, trozo'). 
Capira: poblado de la provincia de Cartago (Istarú). Voz de probable origen huetar, de significado desconocido.

Caragral: poblado perteneciente a Vuelta de Jorco, en la provincia de San José (Caraigres 522 198). Derivado de caregre (caregral pasó a caragral por asimilación), voz de probable origen huetar que designa un arbusto silvestre.

Caraigres: cerro, alto y río de la provincia de San José (Caraigres 521 190, 522191 y 523 193). Voz de probable origen huetar que parece ser variante de caregre (ver Caragral).

Caral: quebrada de la provincia de San José (Abra 510 203). Voz de probable origen huetar, de significado desconocido.

Carara: lomas, poblado, quebrada y río de la provincia de San José (Tárcoles 474 201, 475 198, 476200 y 479 196). Voz de probable origen huetar, de significado desconocido.

Carbri: río de la provincia de Limón (Sukut 578 366). Del cabécar kal 'árbol' y bli 'cauce' ('río del árbol').

Carguicacha: cerro de la provincia de Limón (Siola 553 372). Del cabécar kargi 'selva' y cacháa 'grisáceo, rosado' ('selva grisácea o rosada').

Cariei: río de la provincia de Limón (Estrella 623 196). Según Chang (1999: 108), proviene del cabécar kar 'árbol' y liei 'resbaloso' ('árbol resbaloso').

Caris: quebrada de la provincia de Cartago (Istarú 558 210). Voz de probable origen huetar, de significado desconocido.

Carse: laguna de la provincia de Puntarenas (General 535 336). De origen térraba, de significado no determinado.

Cas: quebrada de la provincia de San José (Abra 533 214) y poblado de la provincia de Cartago (Tucurrique 574 219). Voz de probable origen huetar que designa un árbol y su fruto (Psidium).

Castán: fila de la provincia de Puntarenas (General 534 330). Palabra de origen boruca que significa ‘fila del precipicio' (cas 'precipicio, derrumbe' y tán 'fila').

Catanuria, Catanurio: quebrada y río de la provincia de Alajuela (Arenal 283481 y 281448 ). Voz de origen maleku, de significado no determinado.

Ceriku: río de la provincia de Cartago (Pejibaye 591 187). Voz de origen cabécar (dialecto norteño) que significa 'palenque del grillo', compuesta de shëlëk 'grillo común' y u 'casa'. 
Chamba: quebrada de la provincia de Puntarenas (General 534 331). Voz de origen boruca sin significado primario conocido.

Chares: quebrada de la provincia de Alajuela (Barva 235 518). Voz de probable origen huetar; cha signifia 'hoja comestible' y -res (variante de -gres) es un abundancial, en cuyo caso significaría 'sitio donde abundan las hojas comestibles'.

Chicuá: poblado de la provincia de Cartago (Voz de probable origen huetar que, según tradición oral del lugar, significa ‘ojo de agua' (*chi 'agua' y *cuá 'ojo').

Chimurria: río de la provincia de Alajuela (San Jorge 297 473, Zapote 316 430, San Jorge 297 473, Zapote 316 430, Guatuso 306 428) y también un poblado (Zapote 317 429, 317429 , Guatuso 308 428). Voz de probable origen indígena, pero de lengua desconocida.

Chin Beta: fila de la provincia de Puntarenas (Cabagra 557 345). Voz de origen bribri que significa ‘punta de Chin' (batà 'punta, extremo’ y Chin nombre propio).

China Kichá: poblado del cantón de Pérez Zeledón, en la provincia de San José (Repunta 517 347). Voz de origen cabécar, compuesta de chína 'naranja' y kichá 'raíz'.

Chinaguicha: alto de la provincia de Limón (Siola 553 377). Del cabécar china 'naranja' y gicha 'raíz' ('raíz del naranjo').

Chingori: río de la provincia de Cartago (Tapantí 550 201). Voz de origen cabécar que probablemente significa ‘río del pájaro bobo' (chigó ‘pájaro bobo', ri ‘río’).

Chira: isla, cerro y poblado del golfo de Nicoya (Talolonga). Voz de origen indígena, pero de afiliación desconocida. No se puede determinar si el nombre de la isla, que está documentado en 1519, era el dado por los indígenas de la zona (quizás chorotegas) o dado por otro grupo indígena.

Chires: fila, poblado y río del cantón de Puriscal, en la provincia de San José (Parrita 412 393, 416 390 y Candelaria 495 184). Voz de probable origen huetar, de significado desconocido.

Chirí: río y poblado de la provincia de Cartago (Tapantí 550 201). Voz de probable origen huetar, de significado desconocido.

Chirogres: poblado y río de la provincia de San José (Caraigres 527 198). Voz de probable origen huetar, de significado desconocido. Parece estar compuesta de chiro y del sufijo abundancial -gres. El segmento chiro pareciera tener relación con la especia que Juan Vázquez de Coronado describe como medicinal. De ser la misma, significaría 'lugar donde abunda el chiro'. El problema es que Vázquez de Coronado habla de esta planta como oriunda de Quepos, donde había un grupo indígena con otra lengua distinta a la huetar, a menos que el nombre lo cogiera de los baquianos huetares. 
Chirraca: poblado y quebrada del cantón de Acosta, en la provincia de San José (Caraigres 518200 y Candelaria 487 199). Voz de probable origen huetar, que designa un árbol resinoso (Myroxilon Pereirae).

Chirracal: derivado de Chirraca (ver).

Chirripó: lago y río del cantón de Pérez Zeledón, en la provincia de San José (Durika 519381 y San Isidro 502 375); río, cerro y poblado de la provincia de Cartago (Chirripó 598 199, 599 187, 604 196).Voz de probable origen huetar, de significado desconocido.

Chirripocito: río de la provincia de Cartago (Cuericí 506 394). Derivado de Chirripó (ver).

Chitaría: río y poblado de la provincia de Cartago (Tucurrique 573 206, 581 213). Voz de probable origen huetar, de significado desconocido.

Chiz: poblado de la provincia de Cartago (Tucurrique 568 206). Voz de probable origen huetar, de significado desconocido.

Chomes: poblado de la provincia de Puntarenas (Chapernal 437 225). Voz de indudable origen indígena, pues está documentado como tal en los manuscritos de la Colonia, pero de lengua indígena desconocida. Podría ser de origen chorotega, pues Chomes era un territorio poblado por este grupo indígena, pero no hay palabra de este origen que calce con este nombre, como para dar un probable origen, ni las fuentes coloniales atestiguan su etimología.

Chorosú: finca de la provincia de Alajuela (Tres Amigos 293 509). Voz que parece provenir del huetar, a juzgar por el segmento -su, que aparece en otros topónimos del Valle Central).

Chu: caño de la provincia de Alajuela (Chaparrón 293 508). Voz de probable origen indígena, de lengua desconocida.

Chubá: río de la provincia de San José (Río Grande 503 203). Voz de probable origen huetar, de significado desconocido.

Chubugra: río de la provincia de Puntarenas (Buenos Aires 543 361). Voz de origen bribri, de significado incierto.

Chucás: río y poblado de la provincia de San José (Río Grande 491212 y 493 212). Voz de probable origen huetar, de significado desconocido. Esta palabra parece tener relación con Chucasque, sitio cercano al Río Grande, documentado en 1569 (Quesada Pacheco 1996: 162-163).

Chuguarí: río de la provincia de Cartago (Cuericí 587 187). Voz de origen cabécar que podría provenir de chökkua 'mirlo pardo' (Turdus grayi) y rí 'río', en cuyo caso significaría 'río del mirlo pardo'. 
Chumuri: quebrada de la provincia de Puntarenas (Buenos Aires 543 350). Voz de origen bribri que significa 'río del banano' (de chamù 'banano' y di' 'agua, río'.

Churruca: poblado de la provincia de San José (Abra 532 209). Voz de probable origen huetar, de significado desconocido, pero parece tener relación con churuca (ver).

Churuca (La): otro nombre dado a la ciudad de San Rafael de Oreamuno, en la provincia de Cartago (Istarú 539 210). De acuerdo con un informante de la zona, el lugar significa 'caída de agua', y el pueblo se llama así porque fue fundado cerca de una catarata (Salguero 1991: 115 registra la misma etimología). La Churuca de Oreamuno está documentada en 1798 (Sanabria 1992: 96).

Cirri: poblado y quebrada de la provincia de Alajuela (Naranjo 233 496; Río Grande 500 204 y 501 205)). Voz de probable origen huetar que designa especies de árboles anacardiáceos (Mauria glauca).

Cochey: río de la provincia de Limón (Estrella 636 194). Según Chang (1999: 108) proviene del cabécar kachey 'turbulento'.

Coen: río de la provincia de Limón (Siola 549 373). Según Chang (1999: 108) proviene del bribri kwei 'algo econtrado'.

Conó: quebrada de la provincia de Limón (Siola 548 377). Del bribri konó 'tepezcuinte’.

Coobó: fila y quebrada de la provincia de Puntarenas (Chánguena 538 320). Del boruca cobó ${ }^{\nu}$ 'cerdo de engorde'.

Coris: río, hacienda y poblado de la provincia de Cartago (Istarú 538 206, 540204 y 205). Voz de probable origen huetar, de significado desconocido.

Corobicí: hacienda y poblado de la provincia de Guanacaste (Cañas). Voz de probable origen corobicí, de significado desconocido (ver Bagaces).

Corómbeta: cerro de la provincia de Limón (Siola 567 373). Del bribri kolom 'mamey' y batá 'cerro, cumbre' ('cerro del mamey').

Corrogres: poblado y río de la provincia de San José (Abra 518212 y Río Grande 506 205). Voz de probable origen huetar que parece estar compuesta de corró 'camarón' y el sufijo abundancial -gres, en cuyo caso significaría 'lugar donde abunda el camarón'.

Cot: poblado de la provincia de Cartago (Istarú 551 209). Voz de probable origen huetar, de significado desconocido. Durante el siglo XVI figura escrito como Co o Coo. 
Cote: lago y río de la provincia de Alajuela (Arenal 285437 y 228 442). Voz de origen maleku, de significado no determinado.

Cramancragua: sabana de la provincia de Puntarenas (General 535 335). Voz de origen boruca que únicamente designa dicha sabana, al parecer es un nombre propio.

Crocori: río de la provincia de Limón (Sukut 575 371). Voz de origen bribri, de significado no determinado.

Crori: quebrada de la provincia de Limón (Siola 573 378, Sukut 575 375). Del bribri kro 'ave gallinácea' y di 'agua' ('río de la gallina').

Cuabre: quebrada de la provincia de Limón (Amubri 594 396). Del bribri kwa 'mariposa' y bli 'cauce' ('río de la mariposa'). De acuerdo con Chang (1999: 109), Kwabli o Kwakwari es un nombre mítico donde Sibö transforma las mariposas en mujeres preciosas.

Cuabrí: río y cerro de la provincia de Puntarenas (Kamuk 552 351). Voz de origen bribri que probablemente significa 'río de la caña blanca' (de $u k a$ ' 'caña blanca' y bli 'cauce').

Cuacua: cerro de la provincia de Limón (Telire 561 389). Del bribri kwa'kwa' 'mariposa'.

Cuasrán: cerro de la provincia de Puntarenas (Chánguena 536 324). Del boruca Cuasrán, nombre propio de un ser legendario.

Cubujuquí: poblado de la provincia de Heredia (Guápiles 544 290, 540 249). Palabra de origen huetar cuya primera documentación data de 1777 (Meléndez 1993: 15) bajo la forma Cujuquique. De acuerdo con B. Thiel (cit. por Meléndez, ubi supra), la palabra significa 'lugar donde se halla la casa de Cubuj' (un cacique indígena de la zona). En un manuscrito de 1563 se afirma que Cobux era el lugar del cual Yorusti era cacique. Lo curioso es que la palabra se registra como nombre de lugar, no de persona. Aun así, la traducción que da Thiel (si es que la sacó de la tradición oral, o de sus propias suposiciones, no se sabe) es verosímil, ya que la palabra Cubujuquí permite segmentarse en $C u b u j-u$-qui-ique. En primer lugar, porque está documentado el nombre Cubuj (en su forma antigua Cobux, cuando en el siglo XVI la letra $<\mathrm{x}>$ representaba un sonido palatal fricativo sordo $/ \mathrm{S} /{ }^{12}$; en segundo lugar, porque $u$ podría significar 'casa' en huetar, ya que dicha palabra está documentada en las lenguas chibchas del área, a las que está afiliado el idioma huetar. En tercer lugar, porque existe en huetar una posposición -ique, documentada en la palabra Tayutic Tuyotique, de la cual Juan Vázquez de Coronado (1964: 55) da la traducción 'valle de Tayut', y que se podría traducir por ‘junto a' (Quesada Pacheco 1996: 130- 131). De estas consideraciones se infiere que Cubujuquí Cubujuquique podría significar 'junto a la casa de Cubuj'. Queda, no obstante, el tercer segmento -qui- sin explicación satisfactoria.

Cuchiri: quebrada de la provincia de Limón (Estrella 642 185). Del bribri köchi 'cerdo' y di' 'agua' ('río del cerdo'). 
Cucubres: poblado y río de la provincia de San José (Abra 529209 y 530 207). Voz de probable origen huetar. Parece compuesta de cucú, de significado desconocido, y del sufijo abundancial -bres, -gres.

Cueri: quebrada de la provincia de Limón (Telire 565 392). Del bribri kue' 'tortuga' y di 'agua' ('río de la tortuga').

Cuericí: río y cerros de la provincia de Cartago (Cuericí 493 399, 504 392). Voz de probable origen huetar, de significado desconocido.

Cuij Cuij: sabana de la provincia de Puntarenas (Chánguena 538 326). Voz de origen boruca que designa dicha sabana.

Curari: quebrada de la provincia de Limón (Siola 565 382). Del bribri kulá 'asiento, banca' y di 'agua' ('río de la banca').

Curime: poblado de la provincia de Guanacaste (Matambú). Voz de muy probable origen chorotega. Parece provenir de *curi, de significado desconocido, más el sufijo - me, con el que se forman adjetivos en dicha lengua (cfr. Quirós 1986: 152).

Curirre. quebrada y poblado de la provincia de Alajuela (Arenal 292448 y 293 449). Voz de origen maleku, de significado no determinado.

Curridabat: poblado (Abra 530 207). Voz de origen huetar que designaba un cacique y el lugar donde habitaba. La forma original, que figura en los documentos del siglo XVI, es Curriravá.

Curubandé: poblado de la provincia de Guanacaste (Curubandé). Voz de probable origen chorotega, de significado desconocido.

Curubres: río (Abra 524 203). Voz de probable origen huetar. Parece compuesta de curú, de significado desconocido, y del sufijo abundancial -bres, -gres.

Cuyeo: quebrada de la provincia de San José (Coronado 510 345). Voz de probable origen huetar que designa un ave (Nyctidromus albicollis).

Dabagri: lago de la provincia de Limón (Matama 543 396). Según Chang (1999: 109) proviene del cabécar dabá 'atascarse'.

Dakobri: quebrada de la provincia de Limón (Amubri 574 387). Del bribri dikö 'pejibaye' y bli 'cauce' ('río del pejibaye').

Datsi: cerro de la provincia de Puntarenas (Kamuk 559 354). Voz de origen bribri que significa 'vestido, prenda de vestir'. 
Dechari: quebrada de la provincia de Limón (Siola 556 382). Del bribri decha 'hueso' y di' 'agua' ('río del hueso').

Declarí: río de la provincia de Puntarenas (Buenos Aires 540 361). Voz de origen no determinado, pero al parecer cabécar.

Deuí: río de la provincia de Puntarenas (Kamuk 557 348). Voz de origen bribri que significa 'pavón negro'.

Dibó: cerro de la provincia de Limón (Amubri 589 384). Del cabécar dibo ‘saltado, pronunciado'.

Dibul: cerro de la provincia de Puntarenas (Cabagra 568 344). Voz de origen bribri que significa 'cauce' (diböl).

Dicerire: quebrada de la provincia de Cartago (Pejibaye 583 187). Voz de origen cabécar, de significado no determinado.

Dichata: cerro de la provincia de Limón (Telire 553 391). Según Chang (1999: 110), proviene del cabécar dichá 'hueso más grueso', en cuyo caso el segmento -ta podría provenir de bata 'punta'. De ser así, significaría 'punta del hueso'. Pero también podría provenir de dicháták 'ave traupidácea, tángara'.

Dicheda: quebrada de la provincia de Limón (Siola 570 373). Según Chang (1999: 110) proviene del cabécar dichë 'hueso más grueso'.

Dicoriñak: quebrada de la provincia de Limón (Telire 556 390). Del bribri dikó 'pejibaye', di' 'agua' y ñak 'desembocadura de un río' ('desembocadura del río del pejibaye').

Diká: cerro de la provincia de Limón (Kamuk 559 350). Del cabécar diká 'pejibaye’.

Dikartak: río de la provincia de Limón (Kamuk 559 363). Según Chang (1999: 110) proviene del cabécar y significa 'fracción o parte del pejibaye, tablón del pejibaye'.

Dikeclari: quebrada de la provincia de Cartago (Chirripó 604 198). Voz de origen cabécar que significa 'río de la palma de pejibaye' (dikë ‘de pejibaye' y klö ‘árbol, palo’ y rí 'río').

Dikere: quebrada de la provincia de Cartago (Pejibaye 578 190). Voz de origen cabécar, que significa 'río del pejibaye' dikë 'de pejibaye' y rí 'río').

Dikori: quebrada de la provincia de Cartago (Matama 523 400). Voz de origen cabécar que significa 'río del zorro de agua' (dilkö 'zorro de agua', ri 'río').

Dipali: río de la provincia de Limón (Siola 548 374). Voz de origen bribri que significa 'río del chile' (dipa' 'chile', di' 'río'). 
Diriá: poblado de la provincia de Guanacaste (Diriá). Voz de origen chorotega que, de acuerdo con S. Quirós (1986: 152), significa 'colina, cerro' y proviene de la voz $<$ ntiri> (pronunciado ndiri). Según dicho investigador (íbidem), «Esta forma produjo la castellana diri que, fácilmente, y por influencias de la misma lengua española se convirtió en diriá».

Ditsik: cerro de la provincia de Limón (Durika 533 380). Voz de origen bribri que significa 'saltamontes, chapulín' (ditsik).

Ditsirí Suk: sabana de la provincia de Puntarenas (Buenos Aires 540 357). Voz de origen cabécar que significa 'sabana del río del mastate' (de datsi' dtsi' 'mastate', di' 'río, agua' y sök 'sabana').

Ditsirí: quebrada de la provincia de Puntarenas (Buenos Aires 540 358). Voz de origen cabécar que significa 'río del mastate' (de datsi' $\sim d t s i$ ' 'mastate' y del segmento ri 'río, agua', que figura únicamente en topónimos).

Dlora: quebrada de la provincia de Puntarenas (Buenos Aires 543 357). Voz de origen bribri que significa 'huevo de jilguero' (de dalo' ‘jilguero' y la 'huevo').

Dobóncragua: poblado de la provincia de Puntarenas (General 538 334). Voz de origen térraba, de origen no determinado, pero la primera palabra (dobón) está relacionada con 'tigre'.

Dobonde: quebrada de la provincia de Puntarenas (Buenos Aires 536 351). Voz de origen térraba que significa 'quebrada del tigre' (de dobón 'tigre' y di 'agua, río').

Dobri: quebrada de la provincia de Limón (Siola 571 381). Voz de origen cabécar que significa 'quebrada del zapote' (do 'zapote', bli 'cauce, zanja').

Duchí: quebrada de la provincia de Limón (Matama 541 394). Según Chang (1999: 110) proviene de la voz duchík 'sábalo, pez rocador'.

Duchí: río de la provincia de Cartago (Chirripó 598 199). Voz cabécar que designa la región de Chirripó.

Dudu: cerro de la provincia de Limón (Kamuk 566 355). Voz de origen cabécar que significa 'ave' ( $d u d u$ es reduplicación de $d u$ 'pájaro').

Duedi: quebrada y río de la provincia de Limón (Matama 541 394). Voz de origen bribri que significa ‘río del pavón' (dawë 'pavón', di’ 'agua').

Dueri: quebrada y río de la provincia de Limón (Telire 578 385). Voz de origen bribri que significa ‘río del pavón' (dawë 'pavón', di’ ‘agua’). 
Dukuri: quebrada de la provincia de Limón (Chirripó 602 191). Voz de origen bribri que significa 'río del penacho' (dukö 'pluma, penacho', di' 'agua').

Durega: quebrada de la provincia de Puntarenas (Buenos Aires 541 363). Voz de origen cabécar que significa 'puma' (dulëga).

Durika: cerro de la provincia de Limón (Durika 546 370). Voz de origen bribri que significa 'lugar del árbol del cerro alto' (duli) o del cabécar duleka 'vertical').

Duruy: río de la provincia de Limón (Cahuita 649 184). Voz de origen cabécar que significa 'libélula' (dúriö).

Dusuri: río de la provincia de Limón (Chirripó 611 201). Voz de origen cabécar que significa 'ave fea' (du 'pájaro', sulí ‘feo'). Según Chang (1999: 111) significa 'río del pájaro blanco' (du 'ave', sulu 'blanco', ri 'agua').

Dutú: cerro de la provincia de Puntarenas (Chánguena 542 326). Nombre boruca que significa 'trozo de ñame' (de dú 'ñame' y túj 'pedazo').

Escazú: cerro y poblado (Abra 519206 y 521 212). Voz de probable origen huetar, de significado desconocido. Según la tradición oral, significa ‘piedra de descanso' (Macís 1988, tomo I, p. 15).

Gridum: alto de la provincia de Puntarenas (General 538 330). Nombre boruca que significa 'alto del zopilote' (de urit 'zopilote sin plumas en la cabeza' y drun 'punta').

Guábata: poblado de la provincia de Cartago (Tapantí 556 200). Voz de probable origen huetar, de significado desconocido.

Guágara: quebrada de la provincia de Puntarenas (Repunta 493 352). Voz de probable origen huetar que designa un tipo de palma de cojollo comestible (Chrysophila albida).

Guararí: río, cerro y poblado de la provincia de Heredia (Barva 521 231, 525 235). Voz de muy probable origen huetar, de significado desconocido.

Guaria: poblado y quebrada (Repunta 516 360, Savegre 489 368, Vueltas 467 396, San Isidro 491 367). Según Gagini, es variante de varia 'variada', pero podría ser también de origen indígena, en este caso de origen huetar.

Guary: río de la provincia de Limón (Telire 553 386). Voz de origen cabécar que significa 'río del zorro hediondo' (juá 'mofeta', ri 'río').

Güitite: quebrada (Río Grande 498 206). Voz de probable origen huetar que designa un arbusto (Acnistus arborescens). 
Hobri: quebrada de la provincia de Limón (Sukut 577 383). Voz de origen cabécar que significa 'río del metal'. Ho es, según Chang (1999: 111), una voz secreta que solamente emplean los chamanes en sus cantos; bli 'cauce'.

Ipís: poblado y río de la provincia de San José. Voz de probable origen huetar, de significado desconocido.

Irazú: finca y volcán de la provincia de Cartago (Istarú 551 215, 545 218). Voz de probable origen huetar, de significado desconocido.

Istarú: poblado de la provincia de Cartago. Voz de probable origen huetar, de significado desconocido.

Itiquís: río y poblado de la provincia de Alajuela (Barva 226514 y 223 510). Voz de probable origen huetar que parece tener relación con la voz tiquí 'calabaza para transportar agua' (ver Tiquires).

Izarco: río de la provincia de Cartago (Tucurrique 576 213) y quebrada de la provincia de Alajuela (Barranca 214 479). Voz de probable origen huetar que designa el árbol conocido más comúnmente como ojoche (Helicostylis ojoche).

Jacribeta: cerro de la provincia de Limón (Matama 535 885). Voz de origen cabécar que significa ‘cerro del derrumbe' (jákli o jágli ‘derrumbe’, bata 'punta, cerro').

Jacsini: cerro de la provincia de Limón (Durika 534 383). Voz de origen cabécar que significa 'piedra chica' (jak 'piedra', tsinë 'pequeño').

Jacvaran: quebrada de la provincia de Limón (Estrella 640 187). Voz de origen cabécar que significa 'piedra muy bonita' (ják 'piedra' báa 'bonito', ramá 'muy').

Jakbarari: quebrada de la provincia de Puntarenas (Buenos Aires 541 360). Voz de origen cabécar que significa 'río entre piedras' (de ják 'piedra', balá ‘en medio' y rí 'río').

Jakí: río de la provincia de Cartago (Chirripó 595 186). Voz de origen cabécar con la que se designa dicho río.

Jakúbeta: fila de la provincia de Limón (Siola 558 379). Voz de origen cabécar que, según Chang (1999: 111) significa 'fila de suitas' (jukö 'suita', bata 'punta, fila'). Pero podría también venir de jakú 'carao', en cuyo caso significaría 'fila del carao'.

Jakyaka: sabana de la provincia de Puntarenas (Buenos Aires 541 362). Voz de origen cabécar, al parecer relacionada con ják yaka ‘cemento' (Margery 1989: ítem 1802). 
Jamey: quebrada de la provincia de Limón (Telire 564 395). Voz de origen cabécar que significa 'vena' (jaméi).

Janaveri: quebrada de la provincia de Limón (Telire 559 401). Voz de origen cabécar que, según Chang (1999: 111), significa 'caer en un precipicio o en una profundidad'; en cuyo caso tendría relación con jána ‘caer’ y blí ‘terreno zanjado’ (cfr. Margery 1989: ítemes 1934 y 507).

Japchari: quebrada de la provincia de Limón (Estrella 630 185). Voz de origen cabécar que significa 'piedra dentada' (ják 'piedra', shalëë 'dentado').

Jarbradi: quebrada de la provincia de Limón (Estrella 633 184, 641 186). Voz de origen cabécar que, según Chang (1999: 111), significa 'quebrada de los quelites' (jár 'cualquier planta de hojas comestibles, quelite', bli 'cauce', ri 'agua').

Jaris: poblado y río de la provincia de San José. Voz de probable origen huetar, de significado desconocido.

Jatmarkarí: quebrada de la provincia de Limón (Matama 538 391). Voz de origen cabécar que significa 'río de la piedra colorada' (ják 'piedra', matka 'rojo, colorado', ri 'agua').

Jatsari: quebrada de la provincia de Limón (Chirripó 606 194). Voz de origen cabécar que, según Chang (1999: 112), significa 'cuenca donde por primera vez brota el manantial'.

Jetyukuluri: quebrada de la provincia de Cartago (Chirripó 602 194). Voz de probable origen cabécar, de significado no determinado.

Jorco: río de la provincia de San José. Voz de probable origen huetar que designa un árbol (Rheedia edulis).

Juclori: quebrada de la provincia de Limón (Matama 527 396). Voz de origen cabécar que, según Chang (1999: 112), significa 'quebrada que brota de la base de una casa' (ju 'casa', klö 'pierna, pie', ri 'río').

Jucó: quebrada de la provincia de San José. Voz de probable origen huetar que designa el fruto del calabazo y un árbol (Trema micrantha).

Jupa: poblado de la provincia de San José (Caraigres 511 195). Voz de probable origen indígena pero de afiliación desconocida. Gagini (Diccionario de costarriqueñismos) la cita como empleada también en otras partes de Centroamérica, por lo que su afiliación al huetar parece poco probable.

Jupbiri: quebrada de la provincia de Limón (Matama 538 390). Voz de origen cabécar que, según Chang (1999: 112), significa 'quebrada de la casa que pronto se hace grande'. Pero más bien parece provenir de ju bëryë 'casa grande'. 
Jurami: quebrada de la provincia de Limón (Siola 558 383). Voz de origen cabécar que, según Chang (1999: 112), significa 'quebrada que corre junto a la casa'.

Juray: quebrada, cerro y hacienda de Cartago (Pejibaye 573 201, 574 298). Voz de origen cabécar. Debe ser variante de Jurui (ver).

Juria: quebrada y cerro de la provincia de Cartago (Chirripó 586 187). Voz de origen cabécar que parece significar 'aquella casa abajo' (jú ‘casa' y diá 'aquella abajo'.

Jurui: quebrada de la provincia de Cartago. Voz de origen cabécar con la que se designa dicha quebrada y, en la antigüedad, un palenque situado en la orilla izquierda del río La Estrella (Thiel, cit. por Margery 1989: ítem 2523).

Kabébeta: cerro de la provincia de Cartago (Chirripó 599 192). Voz de origen cabécar que significa 'punta del carrizo' (kabé 'carrizo', bata 'punta').

Kachali: quebrada de la provincia de Limón (Matama 539 390). Voz de origen bribri que significa 'río del achiote' (kacháa 'achiote', di' 'agua').

Kachardi: quebrada de la provincia de Limón (Matama 540 387). Voz de origen bribri que significa 'río del achiote' (kacháa 'achiote', di' 'agua').

Kaí: cerro de la provincia de Puntarenas (Kamuk 549 359). Voz de origen bribri que significa 'pava negra' (kä̈).

Kakébeta: quebrada de la provincia de Limón (Chirripó 608 195). Voz de origen cabécar que proviene de kabé bata y significa ‘cerro del carrizo' (kabé ‘carrizo', bata 'punta, cerro').

Kalkulerí: quebrada de la provincia de Cartago (Chirripó 598 190). Voz de origen cabécar que parece tener afinidad con Karkurí (ver).

Kamagria: quebrada de la provincia de Cartago (Pejibaye 581 186). Voz de probable origen cabécar, de significado no determinado.

Kámuk: cerro de la provincia de Limón (Kamuk 569 358). Voz de origen bribri que, según Chang (1999: 112), significa 'cerro donde hay una especie de pacaya'.

Karbar, Karbrari: quebrada de la provincia de Limón (Telire 555 391). Voz de origen cabécar que, según Chang (1999: 112), proviene de kábar 'quebrada que corre entre las hierbas', de $k a$ 'tierra', bar 'muchas hierbas' y ri 'río'. Pero también podría provenir de kalbá 'cierta clase de hormiga veranera' y ri 'río, agua', en cuyo caso significaría 'río de la hormiga veranera'.

Karkerí: quebrada de la provincia de Cartago (Cuericí 515 401). Voz de origen cabécar, cuyo probale significado es 'río del guácimo' (kal kí 'guácimo', ri ‘río'). 
Karkurí: quebrada de la provincia de Cartago (Pejibaye 586 189). Voz de origen cabécar que probablemente signifique 'río de la hoja de árbol' ( $k a l$ 'árbol', kö 'hoja', rí 'río').

Karverí: río de la provincia de Limón (Telire 554 396). Voz de origen cabécar que significa 'río del árbol' ( $k a l$ 'árbol', bli ‘cauce').

Kasir: cerro de la provincia de Limón (Kamuk 567 350). Voz de origen bribri que proviene de kásir 'saíno'.

Kebé: cerro de la provincia de Puntarenas (Cabagra 565 344). Voz de origen bribri que significa 'quetzal' (kabék).

Keri: quebrada de la provincia de Limón (Telire 570 391). Voz de origen bribri que, según Chang (1999: 112), proviene de kéri ‘orgasmo'.

Keriei: quebrada de la provincia de Cartago (Pejibaye 580 185). Voz de probable origen cabécar, de significado no determinado.

Kichugachari: quebrada de la provincia de Limón (Siola 563 386). Voz de origen cabécar que significa 'río de la raíz de papaya' (kichö 'papaya', gacha 'raíz', ri 'agua, río').

Kicracoro: cerro de la provincia de Limón (Matama 541 389). Según Chang (1999: 113) es voz de origen cabécar que significa 'cerro que parece a los testículos'.

Kiperio: quebrada de la provincia de Limón (Siola 572 372). Voz de origen cabécar que significa 'río del caracol' (kipë 'caracol', ri 'agua, río').

Kirigu: quebrada de la provincia de Limón (Siola 551 370). Voz de origen cabécar que significa 'lagartija' (kirëkö o kirégö).

Kirio: quebrada de la provincia de Limón (Amubri 578 395). Según Chang (1999: 113), es voz de origen bribri o cabécar que significa ‘orgasmo’ (bribri kériö, cabécar kiriö).

Kirióbeta: loma de la provincia de Limón (Amubri 580 398). Voz de origen cabécar que, según Chang (1999: 113), significa ‘cerro del orgasmo' (kiriö 'orgasmo', bata 'punta, cerro').

Kitadikur: quebrada de la provincia de Limón (Estrella 645 196). Según Chang (1999: 113), es voz de origen cabécar que proviene de kita 'sotacaballo' (un árbol) y dakur 'murciélago'.

Kitorí: quebrada de la provincia de Puntarenas (Buenos Aires 540 354). Voz de origen cabécar que probablemente signifique 'río del musgo' (de kitóë 'musgo que suele cubrir las piedras de los ríos' y rí 'río'). 
Kochábeta: fila de la provincia de Limón (Matama 536 388). Según Chang (1999: 113), es voz de origen cabécar que proviene de köskichá 'raíz de roble' y bata 'punta, cerro'.

Koi: quebrada de la provincia de Limón (Telire 588 388). Según Chang (1999: 113), es voz de origen cabécar que proviene de kói 'polvo'.

Korí: quebrada de la provincia de Puntarenas (Buenos Aires 540 355). Voz de origen cabécar que, al parecer, significa 'río de la hoja' ( $k \ddot{o}$ 'hoja', ri 'río').

Korobaria: quebrada de la provincia de Limón (Amubri 583 388). Según Chang (1999: 113), es voz de origen cabécar que proviene de klo 'especie de árbol' y bari 'concentración' ('quebrada donde abunda esta especie de árbol'); pero también podría significar 'manantial del árbol' (klö 'árbol', balë báli 'vertiente, manantial').

Koronono: quebrada de la provincia de Puntarenas (Buenos Aires 543 356). Voz de origen cabécar, de significado no determinado, pero al parecer relacionada con klö 'árbol'.

Kotó: cerro de la provincia de Cartago (Chirripó 581 374). Voz de origen cabécar que significa ‘cielo, firmamento’ (kó ttö).

Kuákua: cerro de la provincia de Puntarenas (Cabagra 566 344). Del bribri kuákua 'mariposa'.

Kuary: quebrada de la provincia de Limón (Telire 557 385). Según Chang (1999: 113), es voz de origen cabécar que proviene de kuatkö 'ortiga'. También podría venir del bribri kuá 'planta' y $d i$ ' 'río, agua', en cuyo caso significaría 'río de plantas'.

Kuisa: quebrada de la provincia de Limón (Siola 548 366). Según Chang (1999: 113), es voz de origen cabécar que proviene de kuë 'tortuga'. Según Thiel (cit. por Margery 1989: 174), es el nombre (escrito Kuesa) de la parte más alta de la Cordillera de Talamanca, donde se separan el valle del rio Coen y el valle de Ujarrás.

Kuitkaviri: quebrada de la provincia de Limón (Chirripó 600 184). Según Chang (1999: 113), es voz de origen cabécar que significa ‘quebrada por donde pasan las tortugas'.

Kuiyé: río de la provincia de Puntarenas (Buenos Aires 542 357). Voz de origen cabécar que probablemente venga de kuyér 'guácimo'.

Kukarí: quebrada de la provincia de Limón (Matama 536 389). Voz de origen cabécar que significa 'río del guacamayo rojo' (kuká 'guacamayo rojo', rí 'agua, río').

Kukó: quebrada de la provincia de Limón (Siola 546 374). Según Chang (1999: 113), es voz de origen bribri que significa 'oreja' ( $k u k o ̈)$. 
Kukúbeta: cerro de la provincia de Limón. Según Chang (1999: 113), es voz de origen bribri que significa 'cerro del tábano' (kakú 'tábano', bata 'punta').

Kulri: quebrada de la provincia de Cartago (Chirripo 603 195). Voz de origen cabécar que significa 'río del guarumo' ( $k \ddot{o}: l$ 'guarumo' y rí 'río').

Kupecereriri: río de la provincia de Cartago (Pejibaye 579 185). Voz de probable origen cabécar, de significado no determinado.

Lari: río, quebrada y alto de la provincia de Limón (Siola 566 376). Voz de origen bribri que significa 'río del niño' (alá 'niño', di’ 'agua, río). Según Chang (1999: 114) también podría provenir del cabécar alari 'río de los duendes' (alar 'duende', ri ‘río').

Lleskila: fila de la provincia de Limón (Matama 450 395). Según Chang (1999: 113), es voz de origen cabécar que significa 'pequeño, diminuto, insignificante' (yuléskë).

Manú: finca de la provincia de Alajuela (Tres Amigos 285 507). Voz de probable origen indígena, de lengua desconocida, que designa un árbol (Minguartia guianensis).

Mari: quebrada de la provincia de Limón (Siola 555 382). Según Chang (1999: 113), es voz de origen cabécar que significa 'colmena, mariaseca' (muliá).

Mok: cerro de la provincia de Limón (Kamuk 566 359). Voz de origen bribri: mók 'murciélago'.

Mokólbeta: fila de la provincia de Limón (Matama 536 388). Voz de origen bribri que significa 'cumbre del arma de fuego' (mököl 'arma de fuego', bata 'punta').

Mome: río de la provincia de Limón (Estrella 637 191). Según Thiel (cit. por Margery 1989: 195) es un islote formado por dos brazos del río La Estrella y significa 'achiote'.

Morein: río de la provincia de Limón (Telire 547 401). Según Chang (1999: 114), es voz de origen cabécar que significa 'pedazos, particulas', en cuyo caso podría provenir de muléi 'polvo'.

Mreduk: lomas de la provincia de Limón (Amubri 584 394). Según Chang (1999: 114), es voz de origen cabécar que signifca 'sabroso'.

Mururbi suk: sabana de la provincia de Puntarenas (Buenos Aires 541 363). Voz de origen cabécar que significa 'sabana del venado' (de mululbí 'venado' y sök 'sabana').

Murusigdio: quebrada de la provincia de Limón (Amubre 581 384). Según Chang (1999: 114), es voz de origen cabécar que significa 'bijagua' (mulukksi o mulusi).

Nai: cerro de la provincia de Limón (Kamuk 565 352). Del bribri o cabécar nai ‘danta’. 
Nambí: poblado de la provincia de Guanacaste (cercano a Nicoya). Del chorotega nambí ‘perro’.

Nambira: fila de la provincia de Guanacaste (Belén). Nombre de origen chorotega que designa la calabaza, usada como recipiente.

Namubak: quebrada de la provincia de Limón (Matama 544 398). Según Chang (1999: 113), es voz de origen bribri que significa 'quebrada por donde pasó el tigre' (namú 'tigre', bak 'pasó').

Namuoki: quebrada de la provincia de Limón (Sukut 580 381). Del bribri namú 'tigre’ y wökir 'cabeza': 'cabeza de tigre'.

Namú-Uorkíbeta: fila de la provincia de Limón (Sukut 586377). Voz de origen bribri que significa 'cumbre de la cabeza del tigre' (namú 'tigre', wökir 'cabeza', bata 'punta, cerro').

Nandamojo: río de la provincia de Guanacaste (Villarreal). Voz de probable origen chorotega, cuyo primer segmento, nanda, significa 'arroyo'; queda sin determinar el segmento mojo.

Nandayure: río, cerro y poblado de la provincia de Guanacaste (Berrugate). Voz de origen chorotega. El segmento nanda significa 'arroyo'; el segundo segmento (yure) no ha sido determinado. La palabra figura documentada en 1599 como nombre de un astillero, jurisdicción del pueblo de Nicoya (L. Fernández 1881- 1907, I; 364- 368).

Nackleri: quebrada de la provincia de Limón (Chirripó 600 182). Según Chang (1999: 115), es voz de origen cabécar que significa 'quebrada donde caen varios ríos, quebrada de varias desembocaduras'.

Nari: quebrada y río de la provincia de Limón (Matama 540 386, Chirripó 605 194). Según Chang (1999: 115), es voz de origen bribri o cabécar que significa 'río impuro' (ña 'excremento, impureza', di' 'agua, río').

Niabri: quebrada y río de la provincia de Limón (Sukut 576 382). Según Chang (1999: 115), es voz de origen cabécar que significa ‘barrigón' (ñá barwí o ñá bëryë ‘barriga'). Pero también podría significar 'río de la barriga' ( $\tilde{a}$ 'barriga', bli 'cauce').

Nicoya: ciudad de la provincia de Guanacaste. Voz de origen chorotega que designaba un cacique y el poblado que administraba. Está documentada desde los inicios de la Colonia.

Nímalas: quebrada de la provincia de Limón (Amubre 586 392). Voz de origen bribri que significa ‘pececito' (nimá ‘pez', -alá ‘diminutivo').

Nimaso: cerro de la provincia de Limón (Siola 569 381). Según Chang (1999: 115), es voz de origen bribri que proviene de namasol 'imponente'. 
Nimboyores: río, cerro y finca de la provincia de Guanacaste (Diriá). Voz de origen chorotega, cuyo primer segmento, nimbo, significa 'agua'; el segmento yores es de significado no determinado.

Nosara: poblado de la provincia de Guanacaste. Voz de muy probable origen chorotega, de significado no determinado.

Ochomogo: cerro y poblado de la provincia de Cartago (Istarú 543 203) y quebrada de la provincia de Alajuela (Río Grande 215 500). Voz de probable origen huetar (chomogo) que significa 'laguna' (Quesada Pacheco 1996b: 191).

Ococa: loma, quebrada y poblado de la provincia de San José. Voz de probable origen huetar, de significado desconocido.

Oka: sabana de la provincia de Puntarenas (Buenos Aires 543 362). Del bribri ôka 'hombro'.

Orosi: río y poblado de la provincia de Cartago (Tapantí 553 198). Voz de origen huetar, de significado desconocido. Su primera documentación data de 1563 como Orocci u Oroc, razón por la cual la palabra da pie para dividirse en el segmento Oroc, de significado desconocido, más el formativo o posposición - $c i$, de significado también desconocido (Quesada Pacheco 1996: 132 y 164).

Orosí: río y volcán de la provincia de Guanacaste (Cacao, Orosí). Voz de probable origen corobicí, la cual permite segmentarse en *oro-, de significado desconocido, más el segmento - $c i$, que parece estar emparentado con el rama si 'agua' (Constenla).

Orotina: poblado de la provincia de Alajuela (Barranca 210 478). Voz de origen chorotega, que designaba un cacique, según relación de Gil González Dávila.

Orotina: quebrada de la provincia de Guanacaste (Belén). Voz que designaba en el siglo XVI a una etnia indígena de la banda oriental del golfo de Nicoya, pero de lengua desconocida.

Orutu: quebrada de la provincia de Limón (Siola 567 371). Según Chang (1999: 113), es voz de origen cabécar que significa 'quebrada donde habitan o donde se encuentran los zopilotes'. Chang agrega que la voz cabécar oló tiene, además, los sentidos de 'claridad' y 'última hoja de una planta, quelite'.

Pacacua, Pacuacua: río y cerro de la provincia de San José. Voz de origen huetar, de significado desconocido. En Bocana de Puriscal la palabra designa una variedad de guineo, pero más bien parece que se llama así por metonimia, donde se tomó el nombre del producto por el nombre del lugar (guineo de Pacaca $\rightarrow$ pacaca).

Pacuar: río y poblado de la provincia de San José. Voz de probable origen huetar, de significado desconocido. 
Pacuare: río de la provincia de Cartago, que sirve de límite con la provincia de Limón (Parismina 613 245). Voz de probable origen huetar, de significado desconocido.

Paré: río de la provincia de Limón (Siola 566 376). Según Chang (1999: 115), es voz de origen cabécar que proviene de paré 'costilla'.

Parruás: río de la provincia de Cartago (Istarú 554 205). Voz de probable origen huetar que designa una planta tintórea, de la cual se extrae un color anaranjado o rojizo, y es usada en artesanía (Arrabidaea chica).

Paso Agres. Ver Agres.

Pasquí: quebrada, cerro y poblado de la provincia de Cartago (Istarú 553 212, 213). Voz de probable origen huetar, de significado desconocido.

Patarrá: poblado de la provincia de San José y río de la provincia de Cartago (Tapantí 547 195). Voz de probable origen huetar que designa una planta rastrera empleada como materia textil (Smilax kunthii).

Picagres: fila, poblado y río de la provincia de San José. Voz de probable origen huetar, que parece estar compuesta de picá, de significado desconocido, y del sufijo abundancial -gres.

Pigres: poblado de la provincia de Alajuela (Tárcoles 197 461). Voz de probable origen huetar, de significado desconocido. La palabra presenta el segmento -gres, empleado para designar abundancia.

Pirgú Krikú: quebrada de la provincia de Puntarenas (Buenos Aires 541 354). Del cabécar pír gö 'anisillo'. El significado de la segunda palabra no está determinado aún.

Pirrís: río de la provincia de Puntarenas (Parrita 427 398). Voz de probable origen huetar, que designa el pájaro llamado comemaíz (Zonotrichia capensis).

Pirro: río de la provincia de Heredia (Abra 523 219). Voz de muy probable origen huetar, de significado desconocido.

Pisirí: quebrada y cerro de la provincia de Cartago (Tucurrique 567 203, 568 202). Voz de probable origen huetar, de significado desconocido.

Piste: fila de la provincia de Limón (Telire 564 384, Siola 565 383). Voz de origen cabécar que significa 'terreno cultivado de ayotes' ( $p i ́ s$ 'ayote', t⿱ë 'terreno cultivado, lugar de cultivo'). 
Pistóbeta: cerro de la provincia de Limón (Chirripó 604 187). Según Chang (1999: 115), es voz de origen cabécar que significa 'cerro donde hay muchos ayotes' (pis 'ayote', të 'terreno cultivado', bata 'cumbre').

Poás: poblado de la provincia de San José. Voz de probable origen huetar, de significado desconocido.

Pocares: finca, río y poblado de la provincia de Puntarenas (Dota 436 391). Voz de muy probable origen huetar, a juzgar por el segmento final -res, que parece tener relación con el abundancial -cris. El segmento pocá- es de significado desconocido.

Pógeres: lomas y poblado de la provincia de Alajuela (Tárcoles 193468 y 192 467). Voz de probable origen huetar, de significado desconocido.

Poró: alto, poblado y quebrada de la provincia de San José, y quebrada de la provincia de Cartago (Tucurrique 569 211, 570 210). Voz de origen huetar que designa varias clases de árboles leguminosos (Erythrina sp.).

Porrosatí: río y poblado de la provincia de Heredia (Barva 524 228, 525 230). Voz de origen huetar que significa ‘quebrada o río de Porrós', según dato de doña María Teresa Sibaja Román, oriunda de San José de la Montaña y descendiente de indígenas de la región. La traducción de dicho hidrónimo es bastante verosímil, ya que, por una parte, y de acuerdo con la estructura gramatical de las lenguas chibchas, a la que pertenece el huetar, en expresiones de posesión el poseedor antecede a lo poseído, de modo que la palabra se puede segmentar en Porrós + tí. Los manuscritos de la época colonial que tienen que ver con antropónimos huetares registran el reduplicado Perrozperroz, Pirrozpirroz o Porrozporroz como nombre de un indígena oriundo de Corroce, en Cartago, que vivió por Tucurrique en 1590 (Quesada Pacheco 1996: 165- 166). Lo que interesa destacar aquí no es proponer a este Porrozporroz como el que le diera origen al río de Heredia, sino más bien corroborar que dicha palabra efectivamente es de origen huetar y que, a juzgar por su presencia en Heredia, fue un nombre empleado tanto uno como a otro extremo del territorio huetar (Quesada Pacheco 1996: 30- 35). Por otra parte, el segmento -tí, que significaría 'agua, quebrada, río', tiene correspondencias con palabras del mismo significado en las demás lenguas chibchas del área. Además, dicho segmento fónico está relacionado con el significado de 'agua' en palabras de muy probable origen huetar, tales como tiquí 'calabaza para transportar agua' y el topónimo e hidrónimo Tibás (ver). En cuanto a la a que une el nombre Porrós con el segmento tí, podría precisamente tratarse de una vocal ligativa.

Pricot: cerro de la provincia de Limón (Siola 570 376). Según Chang (1999: 115), es voz de origen cabécar que significa 'lugar donde hay mucho comején' (pli 'comején', köt 'lugar donde hay mucho animal').

Psei: río de la provincia de Limón (Matama 536 384). Según Chang (1999: 115), es voz de origen cabécar que significa 'río que parece un mecate delgadito'. 
Púcares: río de la provincia de Cartago (Istarú 550 202). Voz de probable origen huetar, de significado desconocido. El semento -res podría ser sufijo abundancial, proveniente de-cris.

Pumbre: quebrada de la provincia de Limón. Según Chang (1999: 115), es voz de origen cabécar que significa 'quebrada que cae, catarata'. Pero más bien parece provenir de $p u ́$ 'ave falcónida' y bli ‘cauce' ('río del gavilán').

Puníbeta: cerro de la provincia de Limón (Siola 546 382). Voz de origen bribri o cabécar que parece provenir de puli 'ceibo' y bata 'cumbre' ('cerro del ceibo').

Purabá: poblado de la provincia de Heredia (Barva 520 224). Voz de muy probable origen huetar, de significado desconocido.

Puribetaria: quebrada de la provincia de Limón (Sukut 579 372). Voz de origen cabécar que significa 'río del cerro del ceibo' (puli ‘ceibo', bata ‘cumbre', ri’ ‘agua, río').

Purires: poblado de la provincia de San José, río y poblado de la provincia de Cartago. Voz de origen huetar, de significado desconocido. La primera documentación de este nombre es Purírici, y data de 1562 (Quesada Pacheco 1992: 167).

Purires: río, hacienda y poblado de la provincia de Cartago (Istarú 540 203, 541202 y 203). Voz de probable origen huetar, de significado desconocido. El semento -res podría ser sufijo abundancial, proveniente de -cris).

Purisil: río y poblado de la provincia de Cartago (Tapantí 557 194). Voz de probable origen huetar, de significado desconocido.

Purral: río y poblado de la provincia de San José. Derivado de purré, voz de probable origen huetar que designa un arbusto (Conostegia lanceolata).

Purruja: quebrada de la provincia de San José. Voz de origen huetar que designa un mosquito, el jején.

Puruses: quebrada de la provincia de San José. Voz de probable origen huetar, de significado desconocido.

Quéquer: río de la provincia de Alajuela (Arenal 290 446). Voz de origen maleku, de significado no determinado.

Queverí: río, cerro y hacienda de la provincia de Cartago (Tapantí 552 190, 554 193, 555 189). Voz de origen cabécar, cuyo probable significado es 'cauce del hermano' ( $k \ddot{e}$ 'hermano', blí ‘cauce').

Quirazú: quebrada y hacienda de la provincia de Cartago (Istarú 541 208, 543 209). Voz de probable origen huetar, de significado desconocido. 
Quircot: poblado de la provincia de Cartago (Istarú 544 208). Voz de origen huetar, de significado desconocido. La palabra en la Colonia era Quircó, Quercó o Quercoc y su primera documentación data de 1563; en 1639 aparece como apellido de un tal Tomás, oriundo de Barva (Quesada Pacheco 1996: 167).

Quirí: río de la provincia de Cartago (Tapantí 552 190). Voz de origen cabécar, cuyo probable significado es 'río del hermano' ( $k \ddot{e}$ ‘hermano', ri ‘río’). Ver Queveri.

Quití: poblado de la provincia de San José. Voz de probable origen huetar, de significado desconocido.

Quizarrá: poblado. Voz de probable origen huetar que designa varias especies de árboles lauráceos (Aiquea costaricensis).

Qutirrisí: poblado y quebrada de la provincia de San José. Voz de probable origen huetar que designa un árbol (Styrax Warzewiczii).

Ruchen: fila y río de la provincia de Puntarenas (General 532 330). Voz boruca que significa 'parte trasera de una embarcación' (de rú ‘embarcación’ y chén? 'parte trasera').

Rujba: quebrada de la provincia de Puntarenas (Chánguena 535 327). Del boruca rújba 'taltuza' (Geomys heterdous).

Sabaum: cerro de la provincia de Limón (Telire 562 391). Según Chang (1999: 116), es voz de origen bribri que significa 'lugar donde se tocan los tambores para la ceremonia de los huesos' (sabak 'tambor', um 'tocar, sonar').

Sacabico: lago de la provincia de Limón (Matama 541 396). Según Chang (1999: 116), es voz de origen cabécar que significa 'lugar donde el lago se deja o quita una persona' (sá 'nuestro' ká 'lugar', bigö 'quitar'). Chang agrega: “Los mayores decían que al cruzar el lago, este se dejaba una persona como retribución, ya que ese lago brindaba mucha comida".

Sákira: cerro de la provincia de Cartago (Vueltas 491 393). Voz de probable origen cabécar, de significado no determinado.

Salpurí: quebrada de la provincia de Limón (Chirripó 608 192). Según Thiel (cit. por Margery 1989: 240), es voz de origen cabécar que significa ‘río del aguilucho’ (sál pú 'aguilucho', ri 'río').

Samen: río, llanos y poblado de la provincia de Alajuela (Guatuso 297 433, 303450 y 297 443). Voz de origen maleku, de significado desconocido.

Sanchirí: poblado de la provincia de Cartago (Tapantí 552 200). Voz de origen huetar, de significado desconocido. 
Sancrahua: fila de la provincia de Puntarenas (Coto Brus 547 311). Del boruca Sancrahua nombre propio de un ser legendario, hijo de Cuasrán.

Sapoá: río de la provincia de Guanacaste (Peñas Blancas). Voz de probable origen indígena, pero de lengua desconocida o no determinada aún.

Sarapiquí: río de la provincia de Heredia (Río Cuarto 531 270). Voz de evidente origen indígena, pero afiliada a una lengua desconocida. La palabra figura en manuscritos del siglo XVI para referirse a dicho río con la variante Siripiqui, el cual, por cruzar el territorio de los indios botos, también se le llamaba Río de los Botos: "que vuestra merced [Licenciado Velázquez Ramiro] haga diligencia acerca del puerto de Sanct Jhoan, que pues el río de los Botos o Ciripiquí es tan grande y tan bueno solo, junto con el otro que se llama Picol, ques tan grande como él, de entender es lo mucho que aventajará en hondura y anchor y sosiego" (Peralta 1883: 641). De lo anterior podría pensarse que la palabra Siripiquí pertenecería a la lengua de los botos; sin embargo, en un manuscrito de 1640 se lee que "seis leguas el río abajo del dicho Desaguadero [hoy el río San Juan] salía un río que tiene por nombre, entre los naturales Jori, y comúnmente nombrado por la gente de mar Siripiquí, que tiene su nacimiento en las cordilleras del dicho pueblo de Barva, envió [el capitán Jerónimo de Retes] cinco hombres a verle y a sondarle, y le hallaron capaz de poder entrar y salir por él cualquier bajel con mucha siguridad, y que sale como doce leguas del mar del Norte y boca del puerto de San Juan, que es la del dicho Desaguadero" (Fernández 1976: 156). Los naturales a los que se refiere el manuscrito son precisamente los indios botos, a los que el capitán Jerónimo de Retes andaba persiguiendo, de modo que no cabe pensar que el hidrónimo fuera de ese origen. Por lo tanto, quedan en la incertidumbre tanto su origen como su significado. Además, dice que la gente de mar, es decir, los marineros españoles, lo llamaban así, de manera que podría ser un nombre importado de una lengua. Por otra parte, el segmento inicial $\mathrm{Si}$ - podría tener relación con la palabra $s i$ 'agua' del rama (cfr. Constenla 1994).

Sarchí: río y poblado de la provincia de Alajuela (Naranjo 226498 y 230 499). Voz de muy probable origen huetar, de significado desconocido.

Sebika: cerro de la provincia de Limón (Matama 533 389). Según Chang (1999: 116), es voz de origen cabécar que significa 'cerro donde hay muchas cicadas' (sëdika 'planta llamada cicada').

Sebror: quebrada de la provincia de Puntarenas (Buenos Aires 538 349; 539 347). Del bribri simbra, de significado desconocido.

Senibri: quebrada de la provincia de Limón (Siola 559 383). Según Chang (1999: 116), es voz de origen cabécar que significa 'río del cariblanco' (saní, siní 'chancho de monte, cariblanco', bli 'cauce').

Shara: río de la provincia de Cartago (Chirripó 599 197). Voz de origen cabécar que designa la localidad de Moravia. 
Shararí: quebrada de la provincia de Cartago (Chirripó 595 190). Voz de origen cabécar que significa 'quebrada de Shara' (compuesto de Shara 'nombre de lugar, Moravia' más rí 'río').

Shebei: quebrada de la provincia de Limón (Telire 566 396). Según Chang (1999: 116), es voz de origen cabécar que significa 'espalda' (shabë).

Sheuab: lomas de la provincia de Limón (Amubri 583 397). Según Chang (1999: 116), es voz de origen cabécar que significa 'camaleón, especie de gavilán' (shuwík wák 'gavilán pequeño').

Sheuí: quebrada de la provincia de Limón (Telire 564 392). Según Chang (1999: 116), es voz de origen cabécar que proviene de Shewik, personaje mítico, primer baquiano que cruzó la Cordillera de Talamanca.

Shiroles: río y quebrada de la provincia de Limón (Telire 573 395). Según Chang (1999: 116), es voz de origen bribri que designa un bejuco medicinal (chiröli).

Shoabrá: riachuelo de la provincia de Puntarenas (Chánguena 544 320). Voz boruca que significa 'mollejón del excremento' (de shuáv 'excremento' y brá ‘mollejón'. El nombre se aplica a una zona del río donde, en tiempos antiguos, se dice que las ancianas del pueblo iban a defecar (comunicación personal de doña Paulina Leiva).

Shukebachari: quebrada de la provincia de Cartago (Chirripó 600 193). Voz de origen cabécar. que significa 'río del algodón tecolote o café oscuro', compuesto de shuké 'algodón', bachá 'café oscuro, tecolote' y rí 'río'.

Siak: quebrada de la provincia de Limón (Siola 567 382). Según Chang (1999: 116), es voz de origen cabécar que designa una piedra mágica (siá).

Silico, Siliko: quebrada y cerro de la provincia de Cartago (Chirripó 594 186). Voz de probable origen cabécar, de significado no determinado.

Simar: quebrada de la provincia de Puntarenas (Coto Brus 572 319). Del bribri tsima 'platanillo'.

Simarí: río de la provincia de Cartago (Pejibaye 577 199). Voz de origen cabécar que significa 'río del platanillo', compuesto de simá 'platanillo' (Heliconia sp.) y rí 'río'.

Sinancra: finca de la provincia de Puntarenas (Chánguena 532 326). Voz del boruca que significa 'palmital' (de sin 'palmito' y ráncra 'sembradío'.

Sinari: quebrada de la provincia de Limón (Sukut 578 370). Voz de origen bribri que significa 'río del perico ligero' (siná 'perico ligero', di' ‘río, agua'). 
Siní: río de la provincia de Limón (Namaki 578 370). Del bribri sini' 'chancho de monte, cariblanco'.

Siola: cerro de la provincia de Limón (Siola 571 375). Según Chang (1999: 117), es voz de origen cabécar que significa 'puntiagudo' (sulëë).

Sipar: fila y río de la provincia de Puntarenas (Kamuk 547 353). Del bribri sipar 'cierta clase de bejuco'.

Sipardia: quebrada de la provincia de Puntarenas (Buenos Aires 545 352). Voz bribri que significa 'río del bejuco' (de sipar 'cierta clase de bejuco' y di' 'agua').

Sipiri: quebrada de la provincia de Cartago (Chirripó 584 189). Voz de origen cabécar que designa el río y la localidad Platanillo.

Sipurio: llanos de la provincia de Limón (Amubri 577 396). Voz de origen cabécar que significa 'lago, laguna' (tsipöriö).

Siquiares: finca y poblado de la provincia de Alajuela (Río Grande 215503 y 217 500). Voz de probable origen huetar, de significado desconocido, donde figura el segmento abundancial -res (que alterna con -gres).

Siquirres: río de la provincia de Limón (Bonilla 588 327). De origen, afiliación y significado desconocidos. Podría provenir del huetar, por el segmento -res, marcador abundancial.

Sirasi: quebrada de la provincia de Limón (Siola 553 377). Según Chang (1999: 116), es voz de origen cabécar que significa 'pizote amarillo' (sirák 'pizote', ksí 'amarillo terroso').

Sirú: quebrada, cerro y finca de la provincia de Cartago (Pejibaye 584 189, 586 188). Voz de origen cabécar que podría provenir de la palabra shirö, la cual designa una clase de avispas grandes y negras.

Sivori: quebrada de la provincia de Limón (Estrella 629 185). Según Chang (1999: 116), es voz de origen cabécar que significa 'río de Dios' (Sibö 'Dios', ri ‘río').

Sixaola: río de la provincia de Limón (Amubri 597 394). Voz de origen miskito que, según Chang (1999: 117), significa 'río de bananos' (sixa 'banano' y ola 'río').

Skra: río de la provincia de Puntarenas (Buenos Aires 537 360). Probablemente del cabécar shkalá 'humo'.

Skub: cerro de la provincia de Limón (Durika 534 377). Voz de origen bribri que significa 'bolso' (sku'). 
Sokurí: quebrada de la provincia de Limón (Siola 557 382). Voz de origen cabécar que significa 'cuello de garrobo' (só 'garrobo', kulí ‘cuello').

Sordi: río de la provincia de Cartago (Tapantí 559 200). Voz de origen cabécar, de significado no determinado.

Sucuri: quebrada de la provincia de Cartago (Matama 521 400). Voz de probable origen cabécar, de signficado no determinado.

Sueo: quebrada de la provincia de Cartago (Cuericí 517 398). Probablemente viene del cabécar que significa 'pez guapote' (suëwö).

Suidiñario: quebrada de la provincia de Puntarenas (Buenos Aires 540 350). Voz bribri que significa 'líquido del excremento del armadillo' (de tsawì tsuwì, ñá 'excremento' y diö 'líquido').

Sujuu: cerro de la provincia de Limón (Matama 540 384). Voz de origen cabécar que significa ‘casa del puercoespín' (sú ‘puercoespin', ju ‘casa').

Suk: cerro de la provincia de Limón (Durika 538 377). Voz de origen cabécar que significa 'sabana' (súk).

Sukui: río de la provincia de Limón. Voz de origen cabécar (sök duí 'especie furnárida, Xenops spp').

Surá: quebrada de la provincia de Heredia (Río Cuarto 535 269). Voz de muy probable origen huetar que designa árboles combretáceos (Terminalia lucida y Terminalia chiriquensis).

Surá: río de la provincia de Puntarenas (Unión 598 326). Del bribri sùla 'lechuza'.

Surari: quebrada de la provincia de Limón (Chirripó 600 184). Voz de origen cabécar. Según Chang (1999:117) significa 'río del padre de la niña Iriria, ser mítico entre los cabécares'. También podría significar 'río de Sulá, espíritu protector de mayor jerarquía entre los cabécares’ (Margery 1989: 266).

Surí: cerro de la provincia de Limón (Durika 542 268). Voz de origen cabécar (sulí o surrí 'guabillo, Inga fagifolia').

Surí: poblado de la provincia de Cartago (Chirripó 603 201). Voz de probable origen huetar que presenta similitud con la palabra capasurí y significa 'venado'. No obstante, puede ser, al igual que Vereh (ver), un nombre histórico, no original, de un cacique boruca llamado Surih, que figura documentado en 1607 (Fernández 1976: 41), puesto por algún historiador o aficionado a la historia. 
Suribeta: fila de la provincia de Limón (Cahuita 652 185). Voz de origen cabécar que significa 'cerro de guabillos' (sulí o surrí 'guabillo, Inga fagifolia'; bata 'punta, cerro').

Surirí: quebrada de la provincia de Limón (Matama 537 389). Voz de origen cabécar que significa ‘río del guabillo' (sulí o surrí ‘guabillo, Inga fagifolia’; ri ‘agua, río').

Súrtuba: quebrada de Pejibaye, en la provincia de Cartago (Pejibaye 586 192). Voz de probable origen huetar que designa una palmera de cogollo comestible (Geonoma edulis, G. Binervia).

Surubre: río de la provincia de Cartago (Barbilla 608 207). Voz de probable origen huetar que designa una palmera (Astrocarium confertum).

Suruy: río de la provincia de Limón (Estrella 636 195). Voz de origen cabécar (surú ‘blanco’).

Tabarcia: poblado y río de la provincia de San José. Voz de probable origen huetar, de significado desconocido.

Tacuatari Tacuatare: cerro de la provincia de San José, en el cantón de Mora. Voz de probable origen huetar, de significado desconocido. El primer segmento parece tener relación con la palabra tacuá, con la que los descendientes de los huetares designan el tepezcuinte (Quesada Pacheco 1996b: 200).

Tanarí: quebrada de la provincia de Cartago (Pejibaye 589 675). Voz de origen cabécar, de significado no determinado.

Tapantí: poblado de la provincia de Cartago (Tapantí 559 195). Voz de probable origen huetar, de significado desconocido.

Tapardí, Taparí: quebrada y río de la provincia de Limón (Matama 538 394, Siola 554379 ). Voz de origen cabécar que significa 'río de la súrtuba' (tapal 'súrtuba'; ri 'río').

Tararia: río y cerro de la provincia de Limón (Kamuk 571 354). Voz de origen cabécar que significa 'río del trueno' (tala ‘trueno'; ri 'río').

Taras: río y poblado de la provincia de Cartago (Istarú 543 206). Voz de probable origen huetar, de significado desconocido. La palabra, escrita Tarax, y que parece tener relación con este nombre, figura en un documento del siglo XVI como nombre de un hombre oriundo de Tucurrique (Quesada Pacheco 1996: 164, 170 y 181).

Tarbaca: poblado, quebrada y río de la provincia de San José. Voz de probable origen huetar, de significado desconocido. 
Tárcoles: cerro de la provincia de San José. Voz de probable origen huetar, de significado desconocido.

Tarrazú: río y poblado de la provincia de San José. Voz de probable origen huetar, de significado desconocido.

Tatiscú: río de la provincia de Cartago (Istarú 549 207). Voz de probable origen huetar, de significado desconocido.

Taus: río de la provincia de Cartago (Pejibaye 564 197). Voz de probable origen huetar, de significado desconocido.

Tayutic: poblado de la provincia de Cartago (Pejibaye 585 201). Voz de origen huetar que significa, según traducción de Juan Vázquez de Coronado, 'valle de Tayut'. Esta traducción da pie para dividir la palabra en dos segmentos: Tayut 'nombre propio' y el sufijo -ic, que parece ser una posposición locativa.

Telire: río de la provincia de Limón (Telire 569 393). Según Chang (1999: 117) es voz de origen cabécar que proviene de tali ‘pez martillo’ y ri ‘agua, río' ('río del pez martillo').

Tempisque: río de la provincia de Guanacaste (Belén). Voz de probable origen nicarao o náhuatl, que designaba una palmera. Voz de muy probable origen azteca: 'tentl', labio, 'pitztic', apretado, y se refiere a un árbol gigantesco de I5 a 20 metros de altura, el cual da frutas dulces cuyo jugo es pegajoso a los labios.

Tiales: río de la provincia de Alajuela (Guatuso 304 441). Voz de origen maleku, de significado desconocido.

Tibás: río y cerro de la provincia de Heredia (Barva 530 229); río y poblado de la provincia de San José (Barva 530 224). Voz de muy probable origen huetar. He recogido dos versiones de la tradición oral respecto de su significado: un informante me dijo que significaba 'agua fría'; otro, 'agua caliente'. Las versiones, que tienen calificativos tan opuestos entre sí, tienen un elemento en común, que sería el que significa 'agua', y que sería el segmento tí (ver Porrosatí). En cuanto a -bás, si en huetar significaba 'caliente', calzaría muy bien con palabras de idéntico sentido en dos lenguas chibchas emparentadas con el huetar, a saber, el cabécar y el bribri: en bribri bámbâ significa 'caliente', y báshbash 'tibio' (Margery 1996: 17); en cabécar, báshkirí, que significa 'caliente' (Margery 1989: 17).

Ticufres: poblado y quebrada de la provincia de San José. Voz de probable origen huetar, de significado desconocido. Según la tradición oral significa 'quebrada honda', que es como también se conoce el lugar.

Tigualba: quebrada de la provincia de San José. Voz de probable origen huetar, de significado desconocido. 
Tiguires: quebrada de la provincia de Cartago (Chirripó 594 200). Voz de probable origen huetar, de significado desconocido. Parece tener relación con la voz tiquí 'calabaza para transportar agua' (Ver Tiquires).

Tilarán: poblado de la provincia de Guanacaste. La palabra aparece documentada en 1783, en donde dice: «La Cordillera de Tilarán, que en lengua yndia significa País y Puerto de muchas aguas» (Biblioteca Nacional [Madrid], ms 18758, fo. 2 v.). El problema es determinar a qué lengua se refieren, pues en guatuso no existe palabra similar para tal significado, y es muy poco probable que sea huetar debido a su composición fonética (cfr. Quesada Pacheco 1996: 114- 126). Lo único que se puede determinar con certeza es que el segmento - $t i$ tiene que ver con el significado de 'agua', como corresponde tanto en guatuso como en huetar (cfr. Quesada Pacheco 1996: 202).

Timacar: quebrada de la provincia de Alajuela (Arenal 292 444). Voz de origen maleku, de significado no determinado.

Tiquires: río y poblado de la provincia de San José. Voz de probable origen huetar, muy probablemente compuesta de tiquí 'calabaza para transportar agua' y -res 'sufijo abundancial' (procedente de -cris), en cuyo caso significaría 'sitio donde abunda la calabaza que transporta agua'.

Tiquirusas: quebrada de la provincia de Guanacaste (Abangares). Voz de probable origen huetar, de significado desconocido.

Tirgrá: quebrada de la provincia de Puntarenas (Buenos Aires 542 356). De origen no determinado.

Tiribí: río de las provincias de San José y Cartago (Abra 536 209). Voz de probable origen huetar, de significado desconocido. Su primera documentación es de 1569 como nombre propio de un cacique principal, subordinado al cacique Aserrí (Quesada Pacheco 1996: 170).

Tirrá: río y poblado de la provincia de San José. Voz de probable origen huetar que designa un árbol (Ulmus mexicana).

Tirurí: hacienda de la provincia de Guanacaste (Villarreal). Voz de probable origen indígena, pero de lengua desconocida o no determinada aún.

Tobosi: cerro y poblado de la provincia de Cartago (Istarú 539 202, Chirripó 597 189). Voz de probable origen huetar, de significado desconocido, pero parece tener afinidad con la palabra tubús o tubusi, que designa un árbol (Vernonia dumeta). El lugar figura ya en un documento de 1609 (Quesada Pacheco 1996: 171).

Tocorí: poblado de la provincia de Puntarenas (Quepos 455 383). Voz de probable origen indígena, de afiliación y significado desconocidos. Por el segmento -rí se podría 
asociar a voces indígenas bribris o cabécares con dicho morfema con el significado de 'río, agua'. Según Garita \& Cordero (2001: 233), los pobladores del lugar asocian el nombre con el de un cacique indígena.

Tonjibe: poblado de la provincia de Alajuela (Arenal 290 450). Voz de origen maleku (Tojifa).

Torrotillo: poblado de la provincia de San José. Derivado de torrote, voz de probable origen huetar que significa 'parte rocosa o pedregosa que queda al descubierto cuando la marea baja'.

Toyogres: río de la provincia de Cartago (Istarú 547 203). Voz de probable origen huetar, de significado desconocido. La forma de la palabra en la Colonia era Toyocris, y figura en documentos de 1632 y 1648 (Quesada Pacheco 1996: 171).

Tsimari: quebrada de la provincia de Limón (Chirripó 609 193). Voz de origen cabécar que significa 'río de la platanilla' (tsima 'platanilla, Heliconia sp'; ri 'río').

Tsinikichá: quebrada de la provincia de Cartago (Chirripó 605 199). Voz de origen cabécar que significa 'raíz del árbol de hule', compuesta de tsini 'caucho' y kichá 'raíz' (dialecto del norte).

Tsipúbeta: lomas de la provincia de Limón (Telire 571 396, Amubri 575 397). Voz de origen cabécar que significa 'cerro de la lombriz' (sipö 'lombriz'; bata 'punta').

Tsiurábeta: fila de la provincia de Limón (Sukut 574 379). Voz de origen cabécar que significa 'cerro del tucancito' (tsiö ‘tucán', -lá ‘diminutivo', bata ‘cerro, punta').

Tsuidi: quebrada de la provincia de Limón (Amubri 579 388). Voz de origen bribri que significa 'río del armadillo' (tsawì o tsuì 'armadillo, di’ 'río, agua').

Tsuitébeta: cerro de la provincia de Cartago (Chirripó 587 184). Voz de origen cabécar cuyo significado parece ser 'cerro del armadillo' (tsui 'armadillo', bata 'punta'). El segmento -te- no está determinado aún.

Tubá: quebrada de la provincia de Cartago (Tucurrique 565 205). Voz de probable origen huetar, de significado desconocido.

Tucurrique: poblado de la provincia de Cartago (Tucurrique 565 204). Voz de origen huetar cuya primera documentación data de 1590 y aparece con muchas variantes: Cucurrique, Currique, Cuquirrique, Quecurrique, Cuquerrique, Cocurrique, Coquerrique, Tuquirrique. Esta gran variación, inusitada en castellano, era posible en huetar, lengua en que las vocales podían intercambiarse, siempre y cuando no llevaran el acento principal; por eso la vocal de la tercera sílaba no varía. En cuanto a las consonantes, podían intercambiarse las oclusivas sordas /t/ y /k/ (escrita <c, qu>). La voz pareciera significar 'el lugar de Coquirre', compuesta de Coquirre o Coquirri 'nombre propio de 
varón' más la posposición locativa -ic, ique . Este nombre propio figura documentado en 1590 como oriundo de Corroce (Quesada Pacheco 1996: 160, 161).

Túfares: cerro y poblado de la provincia de San José. Voz de probable origen huetar, de significado desconocido.

Tuis: río y poblado de la provincia de Cartago (Tucurrique 581 203). Voz de probable origen huetar, de significado desconocido. Figura en un documento de 1705 como un poblado que está a un día de camino de Tayutic hacia Cartago (Quesada Pacheco 1996: 182).

Tunani: río de la provincia de Limón (Siola 568 378). Según Chang (1999: 118) es voz de origen cabécar que está relacionada con el verbo ‘correr' (tuna).

Turales: río de la provincia de Heredia (Barva 527 223). Voz de muy probable origen huetar, de significado desconocido.

Tures: río de la provincia de Heredia (Barva 529 222). Voz de muy probable origen huetar, de significado desconocido.

Turrialba: río, volcán y poblado de la provincia de Cartago (Istarú 563 214, Carrillo 563 222, Tucurrique 570 210). Voz de probable origen huetar, de significado desconocido. Su primera documentación, del siglo XVI, se da bajo la forma turrialua o turriarua (Quesada Pacheco 1996b: 171).

Turrubares: cerro y río de la provincia de San José. Voz de probable origen huetar con que se conoce una paloma silvestre (turubal o turubaria).

Turrúcares: poblado de la provincia de Alajuela (Río Grande 216 502). Voz de muy probable origen huetar, de significado desconocido. La palabra contiene el segmiento turrú, un árbol mirtáceo, cuya palabra es de muy probable origen huetar. El problema es que el turrú se da en zonas de altura, y el sitio donde está Turrúcares es caliente.

Turruja: estero de la provincia de Guanacaste (Tempisque). Voz de probable origen huetar que designa, en la costa del Pacífico, una parte de terreno sin chapodar, en medio de un terreno ya chapodado.

Turú: quebrada y cerro de la provincia de Heredia (Barva 531 227, 531 224). Voz de muy probable origen huetar, de significado desconocido.

Uikuro: cerro de la provincia de Puntarenas (Cabagra 570 340). Probablemente del cabécar wiklö 'tarántula', o bien de wíklö 'fantasma, aparecido'.

Ujarrás: poblado de la provincia de Cartago (Tapantí 555 201). // Poblado de la provincia de Alajuela (Poás 251 516). Voz de origen huetar, de significado desconocido. En Quitirrisí la palabra ojarrá, de evidente similitud con el nombre del lugar, designa un frijol negro, pero no se sabe si el frijol adquirió el nombre de Ujarrás o dicha palabra designaba 
en huetar el frijol negro. El sitio está documentado en el siglo XVI como Uxarraci (pronunciado muy probablemente usharrasi) y da pie para segmentarlo en Ujarrá y el formativo o posposición - ci de significado desconocido. La variante Uxarraz, que da el moderno Ujarrás, figura en 1609 (Quesada Pacheco 1996: 173- 174).

Uká: cerro de la provincia de Puntarenas (Cabagra 659 343). Del bribri $u k a$ ' 'caña blanca'.

Upala: poblado de la provincia de Alajuela (Upala 320 425). Voz de origen maleku que significa 'casa'.

Urán: fila de la provincia de Cartago (Cuericí 516 384). Voz de origen cabécar, de significado no determinado. Thiel (cit. por Margery 1989: 328) lo recoge como nombre de una sabana situada en la parte alta de la región de Ujarrás.

Urasca: río, poblado y hacienda de la provincia de Cartago (Istarú 561 203). Voz de probable origen huetar, de significado desconocido. La palabra parece tener relación con urás 'hijo menor' más el formativo -ca de significado desconocido.

Urén: río de la provincia de Limón (Amubri 580 388). Según Chang (1999: 118) es voz de origen cabécar que signfica 'gusano, oruga' (ulë).

Urí: cerro de la provincia de Limón (Kamuk 563 380). Voz de origen cabécar (urí o urrí 'oso hormiguero').

Uriche: poblado de la provincia de Heredia (Barva 526 521). Voz de muy probable origen huetar, de significado desconocido.

Urrí: quebrada de la provincia de Puntarenas (Coto Brus 572 231). Voz de origen bribri que significa 'oso hormiguero' (urrì).

Urubuk: cerro de la provincia de Puntarenas (Kamuk 557 358). Del bribri urubuk 'tolomuco' (Eira barbara).

Uruca: fila, poblado, quebrada y río de la provincia de San José. Voz de probable origen huetar que designa un árbol (Trinchilia glabra).

Uruchico: cerros y quebrada de la provincia de Limón (Telire 563 396, 564 392). Según Chang (1999: 118) es voz de origen bribri que significa 'deyección del zopilote' (olö 'zopilote'; chka 'sustancia sólida'). Chang agrega que el nombre aparece en la mitología bribri.

Ururí: quebrada de la provincia de Puntarenas (Buenos Aires 539 355). Nombre de origen cabécar que significa 'río de la balsa' (öröö 'balsa' y ri 'río').

Vereh: río, fila y poblado de la provincia de Cartago (Pejibaye 583 193, 588 196). Voz al parecer de origen cabécar que significa 'manantial, vertiente de agua, ojo de agua' (böle). No obstante, la palabra está registrada en un documento de 1607 como el 
nombre de un cacique de origen boruca (Fernández 1976: 41). Llama la atención el hecho de que tanto el poblado cartaginés como el nombre colonial se escriban de la misma forma, tomando en cuenta que en cabécar no existe el sonido /v/ ni hay palabras que terminen en /h/; lo cual da a entender que Vereh es una adapatación gráfica del nombre indígena de 1607 por influjo de algún historiador o aficionado, o por quien oficializara el nombre.

Yabri, Yasbri: quebrada de la provincia de Limón (Telire 562 385). Voz de origen cabécar que significa 'río del mollejón' (ya 'mollejón', bli ‘cauce').

Yan: quebrada de la provincia de Puntarenas (Chánguena 587 325). Del boruca yán? 'beber, comer cosas suaves'.

Yas: quebrada de la provincia de Cartago (Tucurrique 568 218). Voz de probable origen huetar con que se designa un árbol y su fruto (Persea schiedeana).

Yerí: quebrada de la provincia de Puntarenas (Buenos Aires 542 350). Del bribri yëri 'agua termal'.

Yimba: río, fila y poblado de la provincia de Puntarenas (Chánguena 544 326; General 541 329, 540 329). Voz de origen boruca, de significado no determinado.

Yuani: río de la provincia de Limón (Siola 568 379). Según Chang (1999: 118) es voz de origen cabécar que tiene relación con la palabra yua 'racimo de pejibayes o de cocos'.

Yurá: quebrada de la provincia de Puntarenas (Buenos Aires 545 353). Voz que podría tener relación con la palabra bribri yula' 'esclavo'.

Yurui: quebrada de la provincia de Cartago (Pejibaye 583 188). Voz de probable origen caberca, de significado no determinado.

Zurquí: río y cerro de la provincia de Heredia (Barva 532 227). Voz de muy probable origen huetar, de significado desconocido.

\section{Notas}

1. Ver Tilarán en la lista de topónimos.

2. Según comunicación personal con Adolfo Constenla.

3. La documentación colonial costarricense nada nos ha legado sobre estudios que se hicieran durante la Colonia respecto de las lenguas indígenas. Por el momento, las primeras documentaciones que hasta la fecha se conservan de las lenguas indígenas datan de fines del siglo XVIII y se refieren a las lenguas bribri, cabécar y térraba. Son unas listas de lexemas que se irían a emplear en el catálogo de lenguas del mundo, planeado por la reina Catalina de Rusia (L. Fernández 1892). 
4. En adelante empleo la terminología establecida por A. Constenla (1995) para la clasificación y subclasificación de las lenguas chibchas.

5. Opino que es algo apresurado afirmar que no existe del todo, en vista de que no se ha buscado sistemáticamente. Yo, por mi parte, he revisado toda la documentación existente en la sección Guatemala del Archivo General de Indias, pero sin resultados positivos. Por lo menos se sabe que no se encuentra ni en el Archivo Nacional de Costa Rica, ni en el Archivo Eclesiástico de la Curia Metropolitana, de San José. Pero todavía quedan por escudriñar, por ejemplo, el Archivo de Gobierno en Guatemala, el Archivo de la Nación en México, el Archivo General de Indias en Sevilla y el Archivo Vaticano en Roma. Estamos, por lo tanto, frente a una tarea ardua, cuyos resultados no se podrán evaluar hasta que la pesquisa esté agotada.

6. Una lista preliminar aparece publicada en Quesada Pacheco 1990: 32- 58, pero la he modificado y aumentado en mi libro sobre los huetares (1994).

7. Ver la carta del doctor Alonso Criado de Castilla al Rey, en el Archivo General de Indias, Guatemala 12 , sin numeración.

8. Para mayores datos sobre los quepos, consúltese a M. Bozzoli (1976).

9. Dicha lista se encuentra en el Archivo Nacional de Costa Rica, Mortual Cartago 917; folios 45- 45v. Figura publicada, pero con numerosas alteraciones, en C. Quirós 1990: 243. Una nueva versión de esta lista, transcrita directamente de los manuscrritos originales, se halla en Quesada Pacheco 1996c.

10. Por ejemplo, en contraste con el huetar, son frecuentes las grafías $<\mathrm{b}, \mathrm{d}>$ en posición inicial de palabra, y en oposición al boruca, parece haber tenido vocales largas, pues se observan grafías vocálicas dobles en nombres como <Baaraga > y <Ooro> (Quesada Pacheco 1996c: 68).

11. Pienso en nombres de lugar como Balambal, Caracucha, Carbeche, Chai, Chocuana, Rimbaya, etc., tomados de la toponimia de la provincia de Puntarenas (cfr. Garita \& Cordero 2001).

12. Este sonido pasó a uno velar o glotal fricativo sordo, representado por la letra <j>; ver Fernández 18811907, tomo IV, 224).

\section{Bibliografía}

Abarca, Rocío. 1985. "Análisis fonológico del guaymí movere". Estudios de Lingüística Chibcha, Universidad de Costa Rica. 4: 7- 46.

ANEIN (Asesoría Nacional de Educación Indígena); Centro Multinacional de Investigación Educativa. 1988. Necesidades de desarrollo de las comunidades indígenas. San José. Mimeografiado.

Archivo General de Indias: Guatemala 12; Guatemala 181 y Patronato 27, ramo 23, 2.

Archivo Nacional de Costa Rica. Mortual Cartago 917. 
Arroyo, Víctor Manuel. 1971. El habla popular en la literatura costarricense. San José: Oficina de Publicaciones de la Universidad de Costa Rica.

Bauman, J. 1980. A Guide to Issues in Indian Language Retention. Washington: Center for Applied Linguistics.

Benzoni, Girolamo. 1572/ 1962. Dell'Historie del Mondo Nuovo. Venecia. Facsímil. Graz, Austria: Akademische Druck- und Verlagsanstalt.

Biblioteca Nacional (Madrid): Manuscrito 18758. Inédito.

Bolaños, María et al. 1994. Toponimia de la provincia de San José. Tesis de Maestría. Universidad de Costa Rica.

Bozzoli, María Eugenia. 1976. "Los indios quepos de Costa Rica”. En: Antología Femenina del Ensayo Costarricense. San José: Ministerio de Cultura, Juventud y Deportes, 405- 442.

Chang, Giselle. 1999. Toponimia de la provincia de Limón. Tesis de Maestría. Universidad de Costa Rica.

2003. "Bosquejo de los topónimos indígenas de la Región Atlántica”. En: II Congreso sobre Pueblos Indígenas. Del Conocimiento ancestral al conocimiento actual: visión de lo indígena en el umbral del siglo XXI (Universidad de Costa Rica). San José: Sección de Impresión del SIEDIN, 185- 196.

Constenla, Adolfo. 1986a. Abecedario ilustrado malecu. San José: Asesoría Nacional de Educación Indígena, Ministerio de Educación Pública.

1986b. Abecedario ilustrado térraba. San José: Asesoría Nacional de Educación Indígena, Ministerio de Educación Pública.

1988a. "El guatuso de Palenque Margarita: su proceso de declinación”. Estudios de Lingüística Chibcha. 7: 7- 37.

1988b. Abecedario ilustrado guaymí. San José: Asesoría Nacional de Educación Indígena, Ministerio de Educación Pública.

1991. Las lenguas del Área Intermedia: introducción a su estudio areal. San José: Editorial de la Universidad de Costa Rica.

1992. Abecedario ilustrado bribri. San José: Comisión Costarricense de Cooperación con la UNESCO, Comité de Educación. 
1994. "Las lenguas de la Gran Nicoya". Vínculos 18- 19 (1- 2), 191-208. San José, Costa Rica.

1995. "Sobre el estudio diacrónico de las lenguas chibchas y su contribución al conocimiento del pasado de sus hablantes". Boletín Museo del Oro [Bogotá]. 38- 39; 13- 55.

(inédito 1): "El libro de texto para las poblaciones indígenas", en: Seminario taller. Reunión técnica para la revisión de textos en lenguas indígenas. San José: Oficina Subregional de Educación de la UNESCO y Ministerio de Educación Pública. 29 de setiembre de 1993.

Constenla, Adolfo y Espíritu Santo Maroto. 1979. Leyendas y tradiciones borucas. San José: Editorial de la Universidad de Costa Rica.

Conzemius, Eduardo. 1927. “Die Rama-Indianer von Nicaragua”. Zeitschrift für Ethnologie 59: 291- 362.

Coromines, Joan. 1972. Tópica hespérica. Estudios sobre los antiguos dialectos, el substrato y la toponimia romances. (2 vol.). Madrid: Gredos.

Dauzat, Albert. 1971. La toponymie française. Paris: Payot.

Echeverría, Anabelle et al. 1985. Plan de formación en servicio para maestros de las comunidades indígenas de Costa Rica. Universidad de Costa Rica, Facultad de Educación, Escuela de Formación Docente y Asociación Indígena de Costa Rica. Mimeografiado.

Fernández, León. 1881- 1907. Colección de documentos para la historia de Costa Rica. 10 tomos. Barcelona: Imprenta Viuda de Luis Tasso; París: Imprenta Pablo Dupont.

1889. Historia de Costa Rica durante la dominación española. 1502-1821. Madrid: Tipografía de Manuel Ginés Hernández.

1892. Lenguas indígenas de Centro América en el siglo XVIII. San José: Tipografía Nacional.

1976. Indios, reducciones y el cacao. San José: Editorial Costa Rica. Biblioteca Patria.

Ferrero, Luis. 1986. ¿Por qué prehistoria si hay historia precolombina? San José: EUNED.

Gagini, Carlos. 1919. Nuevo diccionario de costarriqueñismos. San José: Imprenta Nacional.

1923. "Documentos para la historia de Costa Rica". Revista de Costa Rica. 5: 79. 
Gallegos, Pedro. 1570. "Relación de lo que he andado y visto de la provincia de Costa Rica. Año de 1570”. En: Academia de Geografía e Historia (1991): Documentos Históricos. San José: Imprenta Nacional; 11-18.

García, Guillermo (asesor): Stsawö we. Texto II para la enseñanza de la lectura y la escritura de la lengua bribri. San José: Asesoría Nacional de Educación Indígena, Ministerio de Educación Pública.

García, Guillermo (responsable). 1992. Adecuación curricular para las escuelas indígenas de Costa Rica (Informe). San José: Ministerio de Educación Pública. Mimeografiado.

García, Guillermo y Xinia Zúñiga. 1987. "Acciones educativas para la revitalización lingüística”. En: Seminario de Revitalización Lingüística. México: I.I.I., C.R.E.F.A.L., U.N.E.S.C.O. Mimeografiado.

Garita, Flor. 1995. Toponimia de la provincia de Cartago. San José: Ministerio de Cultura, Juventud y Deportes; Editorial de la Dirección de Publicaciones. Comisión Nacional de Nomenclatura. Comisión Editorial de la Universidad de Costa Rica.

1997. Toponimia de la provincia de Heredia. San José: Ministerio de Cultura, Juventud y Deportes; Editorial de la Dirección de Publicaciones. Comisión Nacional de Nomenclatura. Ministerio de Obras Públicas y Transportes. Instituto Geográfico Nacional.

1998a. "Toponimia indígena de la provincia de Guanacaste, Costa Rica”. Revista de Filología y Lingüística de la Universidad de Costa Rica. 24 (2): 177- 206.

1998b. "Algunos topónimos indígenas de la provincia de Puntarenas, Costa Rica". Revista Informe Semestral. 34 (enero- diciembre): 77- 89.

Garita, Flor y Humberto Cordero Romero. 2001. Toponimia de la provincia de Puntarenas. San José: Instituto Geográfico Nacional.

Guevara, Marcos y Rubén Chacón. 1992. Territorios indios de Costa Rica: orígenes, situación actual y perspectivas. San José: García Hermanos.

Healy, Paul F. 1974. Archaeological Survey of the Rivas Region, Nicaragua. Tesis doctoral. Department of Anthropology, Harvard University, Cambridge.

Jara, Carla. 1986. Abecedario ilustrado boruca. San José: Asesoría Nacional de Educación Indígena, Ministerio de Educación Pública.

Latorre, Guillermo. 1998. "Sustrato y superestrato multilingües en la toponimia del extremo sur de Chile". Estudios Filológicos (Universidad de Valdivia). 33: 55- 67. 
2001. “Toponimia chilena: "la lejana posesión”. Estudios Filológicos (Universidad de Valdivia). 36: 129- 142.

Lehmann, Walter. 1920. Zentral-Amerika. Teil I. Die Sprachen Zentral-Amerikas in ihren Beziehungen zueinander sowie zu Süd-Amerika und Mexiko. 2 tomos. Berlín: Verlag Dietrich Reimer.

Macís, Alvar. 1988. Apuntes sobre Escazú. 2 tomos. San José: Imprenta Nacional.

Margery, Enrique. 1986. Abecedario ilustrado cabécar. San José: Asesoría Nacional de Educación Indígena, Ministerio de Educación Pública.

1989. Diccionario cabécar-español español-cabécar. San José: Editorial de la Universidad de Costa Rica.

1990. "Estados de conservación de las lenguas indígenas de Costa Rica frente al español". En: Seminario sobre Identidad y modernidad. Nuevos modelos de relaciones culturales. Barcelona, 27-30 de noviembre; 1-7.

1996. Diccionario fraseológico bribri - español español - bribri. San José: Editorial de la Universidad de Costa Rica.

Margery, Enrique y Francisco Rodríguez Atencio. 1991. Narraciones bocotás. San José: Editorial de la Universidad de Costa Rica.

Meléndez, Carlos. 1957. Legislación indigenista de Costa Rica. Instituto Indigenista Interamericano.

1978. Costa Rica vista por Fernández de Oviedo. San José: Ministerio de Cultura, Juventud y Deportes.

1993. Añoranzas de Heredia. Heredia: Editorial Universidad Nacional.

Menéndez Pidal, Ramón. 1968. Toponímia prerrománica hispánica. Madrid: Gredos.

Ministerio de Educación Pública. 1985. Decreto No. 16619-MEP. San José: 9 de octubre de 1985.

1989. Decreto ejecutivo No. 18967-MEP-C. San José: 19 de abril de 1989. Publicado en La Gaceta No. 93 (16 de mayo de 1989).

1993. Decreto Ejecutivo No. 22072-MEP del 25 de febrero de 1993. 
Muntzel, Marta. 1982. "Contribución del español a la pérdida de lenguas mesoamericanas”. En: Actas del I Congreso Internacional sobre el Español de América. [San Juan, Puerto Rico, del 4 al 9 de octubre de 1982]. San Juan: Academia Puertorriqueña de la Lengua Española; 853-863.

Noriega, Félix. 1923. Diccionario geográfico de Costa Rica. San José: Imprenta Nacional.

Peralta, Manuel María. 1883. Costa Rica, Nicaragua y Panamá en el siglo XVI. Su historia y sus límites. Madrid: Librería de M. Murillo.

Portilla, Mario. 1986. "Un caso de muerte de lenguas: el térraba". Estudios de Lingüística Chibcha [Universidad de Costa Rica]. 5: 97- 246.

Potthast-Jutkeit, Barbara. 1998. "Centroamérica y el contrabando por la Costa de Mosquitos en el siglo XVIII". Mesoamérica 36: 499- 516.

Pozas, Ricardo. s.f. Jis ma ishö. México: Litografía Ideal.

Quesada Pacheco, Miguel Ángel. 1990. “La lengua huetar”. Estudios de Lingüística Chibcha [Universidad de Costa Rica]. 9: 7- 64.

1992. "Posición del huetar entre las lenguas chibchas". Estudios de Lingüística Chibcha [Universidad de Costa Rica]. 11: 71- 100.

1996a. Shán rójc brúncajc rójc. Narraciones borucas. San José: Editorial de la Universidad de Costa Rica / Comisión Costarricense de Cooperación con la UNESCO.

1996b. Los huetares: historia, lengua, etnografía y tradición oral. Cartago: Editorial Tecnológica.

1996c. “El idioma de los quepos”. Estudios de Lingüística Chibcha. 15: 59-76.

Quirós, Claudia. 1990. La era de la encomienda. San José: Editorial de la Universidad de Costa Rica.

Quirós, Santiago. 1984. La lengua chorotega o mangue: análisis lingüístico de los materiales existentes. Tesis de Maestría. Universidad de Costa Rica.

1986. "Etimología de los nombres "chorotega", "mangue" y "diriá", en Revista de Filología y Lingüística de la Universidad de Costa Rica. 12 (1): 151- 152.

2002. Diccionario español-chorotega chorotega-español. San José: Editorial de la Universidad de Costa Rica. 
Rojas, Carmen. 1992. "Morfología derivativa de la lengua boruca”, en: Estudios de Lingüística Chibcha [Universidad de Costa Rica]. 11: 35- 64.

Salguero, Miguel. 1991. Cantones de Costa Rica. San José: Editorial Costa Rica.

Sanabria Martínez, Víctor Manuel. 1992. Datos cronológicos para la historia eclesiástica de Costa Rica. San José: Ediciones CECOR.

Sánchez, Juanita y Gloria Mayorga. 1993. Costumbres y tradiciones indígenas. San José: Comisión Costarricense de Cooperación con la UNESCO. Comité de Educación.

Seebach, Karl von. 1865. Prof. K. v. Seebach's Reise durch Guanacaste (Costa Rica), 18641865”. Pertermann's Geographische Mitteilungen. Heft 7: 242.

Tous, Meritxell. 2002. De la Gran Nicoya precolombina a la provincia de Nicaragua, s. XV y XVI. Tesis doctoral. Universitat de Barcelona.

Trapero, Maximino. 1995. Para una teoría lingüística de la toponimia. Universidad de Las Palmas de Gran Canaria: Servicio de Publicaciones.

Universidad Nacional, División de Educación Rural, CIDE, Asociación Nacional de Educadores (1993): Seminario taller: Análisis de la situación indígena en Costa Rica. Programa. 4 - 7 de octubre de 1993. San José: Auditorio de la Asociación Nacional de Educadores, Sede Central. Mimeografiado.

Vázquez de Coronado, Juan. 1964. Cartas de relación sobre la provincia de Costa Rica. San José: Academia de Geografía e Historia.

Zúñiga, Agustín. 1990. Pueblos indígenas de Costa Rica, San José: Ministerio de Educación Pública, Asesoría Regional de Educación Indígena. Mimeografiado.

\section{Internet}

http.//www.fidh.org/IMG/pdf/costarica2002cerd.pdf (consultada el 20 de agosto de 2007).

Tort, Joan. 2001. "La toponímia com a camp de coneixement interdisciplinari. algunes bases teòriques i epistemològiques per a l'estudi dels noms de lloc". Scripta Nova. Revista electronica de Geografia y Ciencias Sociales de la Universidad de Barcelona. 86; 1 de abril de 2001. (http.//www.ub.es/geocrit/sn-86.htm) 
